Article

\title{
Evaluation of Linear Deformation and Unloading Stiffness Characteristics of Asphalt Mixtures Incorporating Various Aggregate Gradations
}

\author{
Mujasim Ali Rizvi ${ }^{1}$, Ammad Hassan Khan ${ }^{1, * \mathbb{C}}$, Zia ur Rehman ${ }^{1}$, Aasim Inam ${ }^{2}$ and Zubair Masoud ${ }^{3}$ \\ 1 Department of Transportation Engineering and Management, University of Engineering and Technology \\ Lahore, Lahore 54890, Pakistan; mujasimalirizvi@uet.edu.pk (M.A.R.); gzia718@uet.edu.pk (Z.u.R.) \\ 2 HRTC \& Design, National Highway Authority of Pakistan, Islamabad 44090, Pakistan; aasiminam@gmail.com \\ 3 Geotechnical Consultant, Lahore 54810, Pakistan; 978.xyz@gmail.com \\ * Correspondence: chair-tem@uet.edu.pk
}

check for

updates

Citation: Rizvi, M.A.; Khan, A.H.; Rehman, Z.u.; Inam, A.; Masoud, Z. Evaluation of Linear Deformation and Unloading Stiffness

Characteristics of Asphalt Mixtures Incorporating Various Aggregate Gradations. Sustainability 2021, 13, 8865. https://doi.org/10.3390/ su13168865

Academic Editor: Rui Micaelo

Received: 27 May 2021

Accepted: 2 August 2021

Published: 8 August 2021

Publisher's Note: MDPI stays neutral with regard to jurisdictional claims in published maps and institutional affiliations.

Copyright: (c) 2021 by the authors. Licensee MDPI, Basel, Switzerland. This article is an open access article distributed under the terms and conditions of the Creative Commons Attribution (CC BY) license (https:// creativecommons.org/licenses/by/ $4.0 /)$.

\begin{abstract}
Optimum stiffness and linear deformation in the unloading phase are fundamental properties of asphalt mixtures required for the durability of flexible pavements. In this research, blends of six different aggregate gradations were used for two base course (BC) and four wearing course (WC) asphalt mixtures. Stability and indirect tensile strength of resulting asphalt mixtures were evaluated to relate to viscoelastic unloading deformation and resilient moduli (instantaneous (MRI) and total (MRT)) at $25^{\circ} \mathrm{C}$ using a $40 / 50$ binder for 0.1 and $0.3 \mathrm{~s}$ load durations. Results indicated that an increase in coarse aggregate proportion from 48 to $70 \%$ for BC has shown a $12 \%$ and $14 \%$ increase in MRT for 0.1 and $0.3 \mathrm{~s}$ load durations, respectively, and an increase in coarse aggregate proportion from 41 to $57.5 \%$ for WC has caused a $26 \%$ and $20 \%$ increase in MRI for 0.1 and $0.3 \mathrm{~s}$ load durations, respectively. The same coarse aggregate proportions showed an increase in linear viscoelastic deformation at $0.1 \mathrm{~s}$ load duration from 54.6 to $68.2 \%$ for WC and from 53.0 to $62.7 \%$ for BC, whereas for $0.3 \mathrm{~s}$ load duration linear viscoelastic deformation increased from 58.1 to $69.1 \%$ for WC and 64.3 to $69.2 \%$ for BC. The findings of this study will assist in the selection of aggregate gradations to be used in wearing and base course asphalt mixtures for pavement design, construction and maintenance.
\end{abstract}

Keywords: asphalt mixture; resilient modulus; viscoelastic deformation; aggregate

\section{Introduction}

Resilient modulus (MR) is the key parameter used for the design, evaluation, performance and analysis of flexible pavements [1]. In mechanistic-empirical design and analysis of flexible pavements, the stiffness properties of materials in different layers are related to stresses and strains induced by vehicle loading, hence the main outcome of stress-strain behavior, i.e., resilient modulus is an essential parameter to be used for the assessment of rutting and fatigue [2-4]. The elastic modulus is evaluated as a ratio of stresses and strains in monotonic loading, whereas the resilient modulus for the pavements is determined from repeated loading in different waveforms, usually haversine, which closely simulates the traffic loading [5]. The resilient modulus of asphalt mixtures depicts the relative strength coefficient and structural number (SN) used in the design of flexible pavements [6]. MR value is considerably affected by the loading type, loading time (vehicle speed) and mix type [7,8]. The resilient modulus decreases with an increase in temperature [9]. A change in stress level exhibits a change in deformation which further depicts the resilience of the asphalt mixture [9].

In recent years various researchers have carried out experimentation on the stiffness properties of asphalt mixtures [10-12]. The effect of mixture stiffness on the fatigue life of asphalt pavements was investigated [13-15]. Different studies were performed to assess 
the durability of laboratory-prepared asphalt mixtures [16-18]. The influence of volumetric properties on the performance of asphalt mixtures was evaluated [19-22]. Extensive past studies are seen to explore the effects of different types of aggregate gradations on the evaluation of MR of asphalt mixtures. The resilient modulus is significantly affected by a change in aggregate type and aggregate gradation [23]. The effects of aggregate gradation and nominal maximum aggregate size on the resilient modulus of asphalt mixes at $25^{\circ} \mathrm{C}$ was also experimentally investigated [24]. It was evaluated that significant improvements in resilient modulus of asphalt mixes were observed when coarse aggregates with more irregular morphologies were used. The effect of maximum aggregate size on resilient modulus was investigated [25]. Five gradations of aggregates with maximum aggregate sizes of $3 / 8,1 / 2,3 / 4,1$ and 1.5 inches were employed and a good correlation between the resilient modulus and the maximum aggregate size was found. Accordingly, the resilient modulus increases as the maximum aggregate size increases. The effect of diameter/maximum nominal aggregate size ratio was investigated, and it was found that the resilient modulus of asphalt mixtures decreases as the ratio increases [26].

The impact of bitumen and aggregate combination on resilient modulus using four bitumen grades and four aggregate types were explored [27]. The asphalt mixtures with lower penetration grade bitumen exhibited higher resilient modulus and tensile strength, in dry and wet conditions, than those with higher penetration grades.

ASTM D 7369 explains the deformation caused by traffic loading as instantaneous and total deformation. Instantaneous deformation is very significant in the sense that the vehicle load induces deformation in a very short interval of time, whereas total deformation corresponds to the total duration of the application of load. The behavior of asphalt mixtures with different aggregate proportions and binder grades has rarely been studied for deformation caused by vehicle loads for very short intervals of time and total duration of applied load. Rare experimentation is seen in the literature on the role of different aggregate gradations and proportions of coarse aggregate on the instantaneous and total deformation caused by traffic loading for $0.1 \mathrm{~s}$ and $0.3 \mathrm{~s}$ load durations at $25^{\circ} \mathrm{C}$.

Asphalt mixtures exhibit viscoelastic behavior [28] (combination of elastic and viscous responses) when subjected to repeated vehicle loads. The non-linear viscoelastic properties of asphalt mixtures are significant for the prediction of pavement performance as asphalt pavements present non-linear behavior when subjected to heavy traffic loads [29]. Recoverable strain energy (RSE) is an important parameter for the assessment of asphalt mixtures to store and recover energy [30]. RSE is evaluated from the viscoelastic portion of the load-deformation curve of the resilient modulus test. The deformation curve for the haversine pattern of repeated loading presents two portions, i.e., viscoelastic and viscoplastic portions, where the viscoelastic portion further comprises linear viscoelastic and non-linear viscoelastic deformation. The RSE decreases with an increase in the number of cycles due to the loss of ability of the asphalt sample to store and recover energy as the particles of the sample become loose by repeated loading. The linear viscoelastic deformation is fully recoverable whereas the non-linear viscoelastic portion of the deformation curve is significant as the basis for further disturbances in samples with an increase in the number of cycles. Asphalt mixtures with larger extents of linear viscoelastic and lesser extents of non-linear viscoelastic deformation are considered good quality due to highly elastic behavior against dynamic loads.

It is well established that resilient modulus depends on the properties of binders and aggregates. However, the effect of variation in aggregate gradation and proportion on linear deformation and unloading stiffness is rarely seen in the literature. Therefore, in this research a range of different aggregate gradations and proportions were blended with a single binder to distinguish the effects of aggregate gradations and proportions clearly. The study was specifically oriented to the effects of aggregate gradation on the cyclic properties of asphalt mixtures. As a result, the gradation simulating the typical construction material encountered at road projects, with optimum resilient modulus, can be adopted in pavement construction projects to achieve economy. 
The effect of coarse aggregate proportions of different gradations and proportions on resilient modulus and linear and non-linear viscoelastic deformation is rarely seen in the literature, although this aspect is vital in the assessment of the performance of asphalt mixtures. The specific objectives of the study were to evaluate the effect of aggregate gradation and proportion on the stiffness and viscoelastic deformation of asphalt mixtures for flexible pavements.

1. Comparison of MRI and MRT with load duration, i.e., $0.1 \mathrm{~s}$ and $0.3 \mathrm{~s}$.

2. Comparison of linear and non-linear viscoelastic deformation induced during $0.1 \mathrm{~s}$ and $0.3 \mathrm{~s}$ load durations for WC and BC.

3. Relation of coarse aggregate proportion versus instantaneous and total resilient moduli (i.e., MRI and MRT).

4. Relation of stability, density and indirect tensile strength (ITS) versus MRI and MRT.

\section{Materials and Methods}

The materials used in this research are the asphalt binder and aggregate, which are characterized by laboratory testing.

\subsection{Asphalt Binder}

Asphalt binder was acquired from National Refinery Limited (NRL), Karachi, Pakistan. Asphalt binder was characterized by conventional tests such as penetration (ASTM D5) test [31], softening point (ASTM D36) test [32], ductility (ASTM D113) test [33] and flash point (ASTM D92) test [34]. The results of conventional tests are given in Table 1a.

Table 1. Results of asphalt binder (a) conventional properties (b) performance-based properties.

\begin{tabular}{|c|c|c|c|c|}
\hline \multirow{2}{*}{ Parameter } & \multicolumn{4}{|c|}{ Result } \\
\hline & $\mathrm{S} 1^{1}$ & $\mathrm{~S} 2$ & S3 & Average \\
\hline \multicolumn{5}{|c|}{ (a) } \\
\hline Penetration (0.1 mm) & 47 & 48 & 45 & 47 \\
\hline Flash Point $\left({ }^{\circ} \mathrm{C}\right)$ & 335 & 336 & 333 & 335 \\
\hline Ductility (cm) & 121 & 119 & 122 & 121 \\
\hline Softening Point $\left({ }^{\circ} \mathrm{C}\right)$ & 51.5 & 52.0 & 51.3 & 51.6 \\
\hline Solubility (\%) & 99.91 & 99.76 & 99.93 & 99.87 \\
\hline \multicolumn{5}{|l|}{ 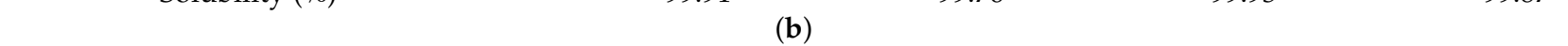 } \\
\hline Viscosity at $125^{\circ} \mathrm{C}\left(\mathrm{cP}^{2}\right)$ & 812.5 & 820.5 & 803.5 & 812.2 \\
\hline Viscosity at $135^{\circ} \mathrm{C}(\mathrm{cP})$ & 462.5 & 450.5 & 475.5 & 462.8 \\
\hline Viscosity at $145^{\circ} \mathrm{C}(\mathrm{cP})$ & 287.5 & 289.5 & 285.5 & 287.5 \\
\hline Viscosity at $155^{\circ} \mathrm{C}(\mathrm{cP})$ & 187.5 & 184.5 & 189.5 & 187.2 \\
\hline Viscosity at $165^{\circ} \mathrm{C}(\mathrm{cP})$ & 125.0 & 122.0 & 128.0 & 125.0 \\
\hline Viscosity at $175^{\circ} \mathrm{C}(\mathrm{cP})$ & 87.5 & 84.5 & 89.5 & 87.2 \\
\hline Viscosity at $185^{\circ} \mathrm{C}(\mathrm{cP})$ & 62.5 & 60.5 & 64.5 & 62.5 \\
\hline $\begin{array}{c}\text { True Grade Temperature }\left({ }^{\circ} \mathrm{C}\right) \\
\text { (Original) }\end{array}$ & 70.5 & 70.0 & 71.0 & 70.5 \\
\hline True Grade Temperature $\left({ }^{\circ} \mathrm{C}\right)(\mathrm{RTFO})$ & 67.5 & 68.0 & 67.0 & 67.5 \\
\hline True Grade Temperature $\left({ }^{\circ} \mathrm{C}\right)(\mathrm{PAV})$ & 23.5 & 24.0 & 23.0 & 23.5 \\
\hline BBR Low Temperature $\left({ }^{\circ} \mathrm{C}\right)$ & -10.1 & -10.0 & -10.3 & -10.1 \\
\hline Performance Grade & PG 64-16 & & & \\
\hline
\end{tabular}

${ }^{1}$ S1: Sample 1, S2: sample 2, S3: sample $3 ;{ }^{2}$ cP: centipoise.

The performance-based properties of asphalt binder were determined using performancegraded (PG) binder specifications AASHTO M-320 [35]. These properties were determined using a rotational viscometer (RV), dynamic shear rheometer (DSR), rolling thin film oven (RTFO), pressure aging vessel (PAV) and bending beam rheometer (BBR). The test conditions are briefly discussed in the following lines.

The rotational viscosity test was performed to check the mixability and workability of the asphalt binder. Rotational viscosity values were obtained in accordance with AASHTO 
$\mathrm{T} 316$ [36]. The rotational viscosities were determined at seven temperatures ranging from $125^{\circ} \mathrm{C}$ to $185^{\circ} \mathrm{C}$.

The viscoelastic properties of the asphalt binder were determined using a dynamic shear rheometer (DSR) in accordance with AASHTO T 315 [37]. The DSR test was conducted under a stress-controlled loading condition using $1.59 \mathrm{~Hz}$ frequency at high$\left(46-82{ }^{\circ} \mathrm{C}\right)$ and intermediate $\left(7-31^{\circ} \mathrm{C}\right)$ temperature ranges. Samples were tested in original, rolling thin film oven (RTFO)-aged and pressure aging vessel (PAV)-aged conditions. The RTFO test was performed to simulate the short-term aging of binders as per AASHTO $\mathrm{T} 240$ [38]. The PAV test was performed on RTFO-aged samples following AASHTO R 28 [39] to simulate the long-term aging effects.

In order to measure the low-temperature cracking performance of the asphalt binder, a BBR test was performed in accordance with AASHTO T313 [40]. The creep stiffness (S) and M-value of PAV-aged samples were determined at three different temperatures: $-6,-12$ and $-18{ }^{\circ} \mathrm{C}$. The $\mathrm{S}$ and $\mathrm{M}$-values were used to determine the low-temperature performance grade.

\subsection{Aggregate}

The aggregate samples of different sizes were selected from a quarry of limestone with high impact and crushing strength, therefore they are widely used in pavement construction with high traffic loads [41]. The same stone quarry was selected for wearing course (WC) and base course $(\mathrm{BC})$ in the present study to clearly distinguish the effect of gradation on linear deformation and unloading stiffness. This study employed four wearing course gradations and two base course gradations. Wearing course (WC) gradations included D-4, D-5 based on ASTM D 3515 [42], Superpave (SP-B) [43] and Asphalt Institute Manual Series (MS-)2 [44]. Base course (BC) gradations utilized Superpave (SP-2) [43] and dense bound macadam (DBM) [45]. These gradations are the most frequently used gradations for both WC and BC mixtures worldwide. This choice of gradations would make the findings of this study globally acceptable. The aggregates were tested by performing tests which include fractured faces, flakiness index, elongation index, Los Angeles abrasion value, water absorption, soundness, uncompacted voids and sand equivalent in accordance with relevant prevailing standards. The aggregate test results are summarized in Table 3.

\subsection{Marshal Mix Design}

The optimum asphalt content $(\mathrm{OBC})$ of asphalt mixtures was determined using the Marshall mix design method in accordance with ASTM D 6926 [46]. The target air voids were kept at $4 \%$ and all volumetric parameters were checked against the recommended values at target air voids.

\subsection{Asphalt Mixtures}

Asphalt mixtures were prepared by blending each aggregate gradation with optimum bitumen content $(\mathrm{OBC})$ determined from the Marshall mix design method. Four WC and two BC mixtures involving a 40/50 binder and six gradations, D4, SP-B, D5, MS-2, DBM and SP-2, were utilized for the determination of Marshall test properties, indirect tensile strength and resilient modulus. After the blending process, the mixtures were left in an oven for two hours to meet the short-term aging criteria. Specimens for indirect tensile strength (ITS) and resilient modulus (MR) tests were prepared using gyratory compactor AASHTO-T 312 [47] after heating the asphalt mixtures to their compaction temperatures.

\subsection{Indirect Tensile Strength (ITS) Test}

The indirect tensile strength (ITS) test was performed to determine the tensile properties of gyratory-compacted WC and BC asphalt mixtures as per ASTM D 6931 [48]. The ITS values of asphalt mixtures were determined at $25^{\circ} \mathrm{C}$ using a universal testing machine (UTM) with digital loading and temperature control systems. The indirect tensile strength of samples was determined by applying a compressive load along a diametrical plane 
through two opposite loading strips as shown in Figure 1. Prior to testing, the specimens were conditioned in the temperature-controlled chamber for $4 \mathrm{~h}$. The wearing course samples had $50.4 \mathrm{~mm}$ thickness and $99 \mathrm{~mm}$ diameter whereas base course samples had $76.2 \mathrm{~mm}$ thickness and $147.3 \mathrm{~mm}$ diameter. As per ASTM D6931-07, a minimum specimen height of $75 \mathrm{~mm}$ is required for specimens with a nominal diameter of $150 \mathrm{~mm}$. As the diameter of BC specimens is $147.3 \mathrm{~mm}$, the thickness of $76.2 \mathrm{~mm}$ was used. ITS was calculated using Equation (1).

$$
S t=\frac{2000 P}{\pi D T}
$$

where:

$S t=$ Indirect tensile strength of specimen $(\mathrm{kPa})$

$P=$ Maximum value of load taken by specimen before failure $(\mathrm{N})$

$D=$ Diameter of specimen $(\mathrm{mm})$

$T=$ Thickness of specimen $(\mathrm{mm})$
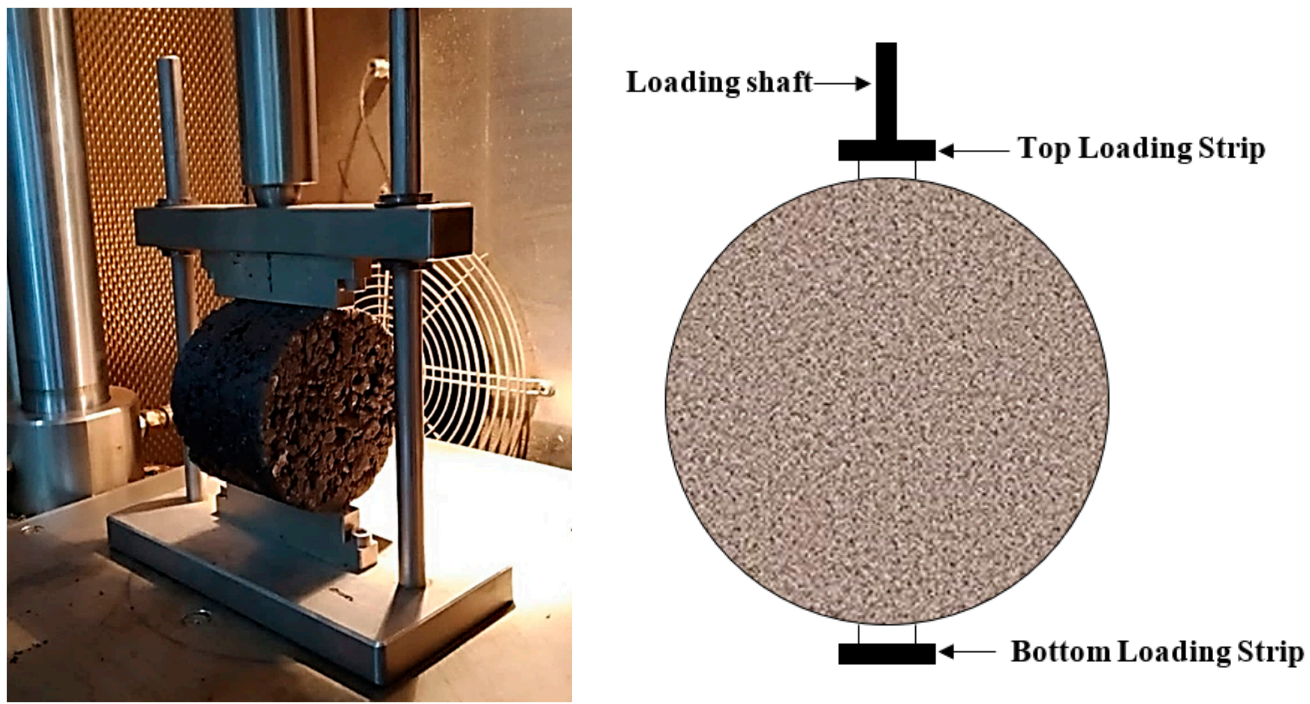

Figure 1. Test setup for indirect tensile strength tests in UTM.

\subsection{Resilient Modulus (MR) Test}

Resilient modulus test on both WC and BC asphalt mixtures was conducted as per ASTM D 7369 for the evaluation of instantaneous (MRI) and total (MRT) resilient moduli. MR value of asphalt mixtures was determined using a UTM as shown in Figure 2. The load was applied on the specimen through the top loading strip along the diametral axis of the specimen. The contact area of the loading strip was $12.7 \mathrm{~mm}$ and $19 \mathrm{~mm}$ wide for WC and $\mathrm{BC}$ asphalt mixtures, respectively.

The test temperature $\pm 0.5^{\circ} \mathrm{C}$ was maintained in the temperature-controlled chamber throughout the conditioning and testing period. The applied loads and the resulting deformations were measured and recorded through a load cell and a set of linear variable differential transducers (LVDTs), respectively. The load and deformation measurements were monitored continuously through a data acquisition system capable of recording 500 scans per second. Both horizontal and vertical deformations of the specimens were measured by mounting two LVDTs through glued studs on each face. The gauge length was $43 \mathrm{~mm}$ and the LVDTs were mounted between gauge points along the horizontal and vertical diameters. The horizontal and vertical alignment of LVDTS were ensured through an alignment device, and the diametral axes were marked.

The wearing course samples had $50.4 \mathrm{~mm}$ thickness and $99 \mathrm{~mm}$ diameter whereas base course samples had $50.4 \mathrm{~mm}$ thickness and $147.3 \mathrm{~mm}$ diameter. Three specimens of each mixture were tested for two loading durations ( 0.1 and $0.3 \mathrm{~s})$ at a temperature of $25^{\circ} \mathrm{C}$. 


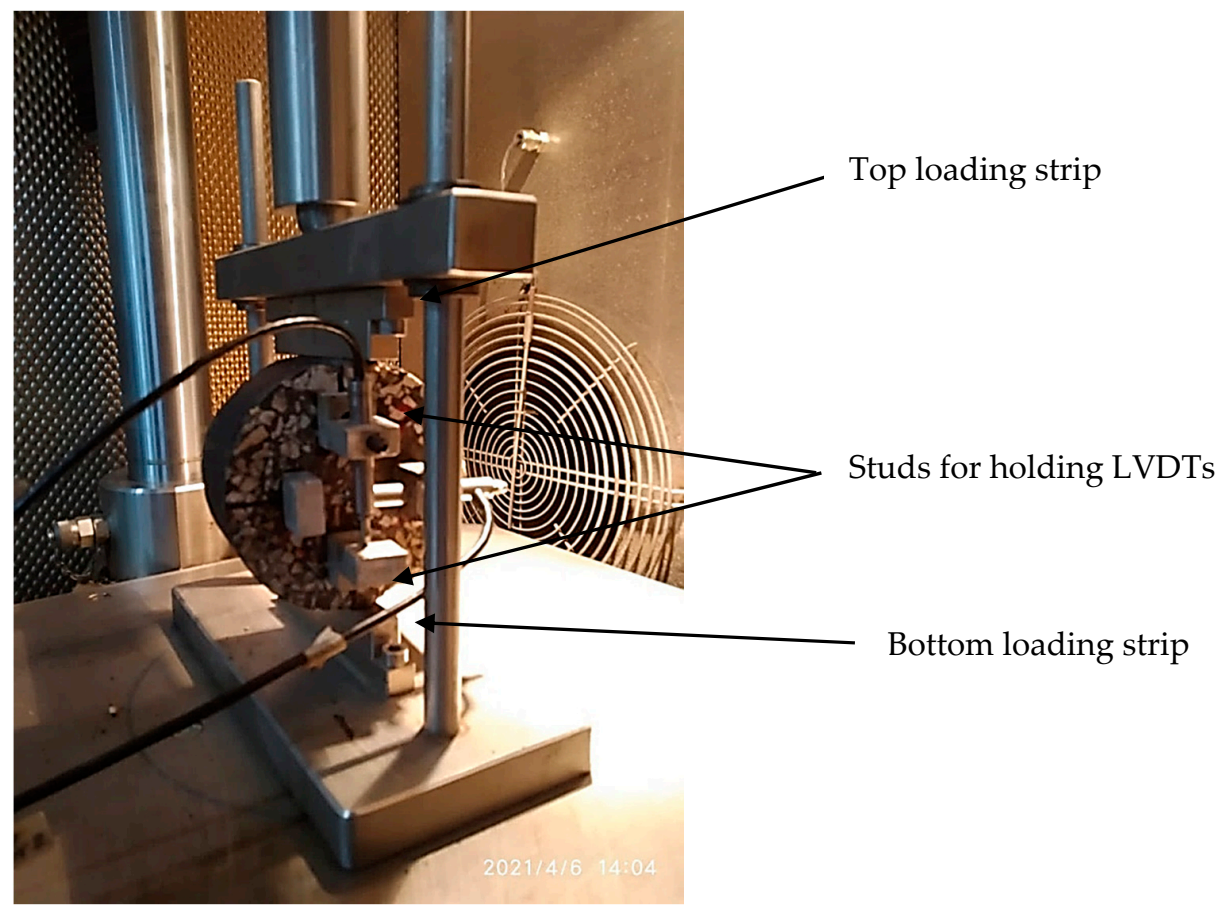

Figure 2. Test setup for resilient modulus tests in UTM.

Prior to testing, the specimens were conditioned in the temperature-controlled chamber for $6 \mathrm{~h}$. A cyclic haversine loading scheme at frequencies of $0.1 \mathrm{~Hz}$ and $0.3 \mathrm{~Hz}$ were applied with $0.9 \mathrm{~s}$ and $0.7 \mathrm{~s}$ dwell time, respectively. In each loading sequence the total load was the sum of the cyclic load and the contact load (i.e., load to keep the sample in touch with loading plunger of the UTM). The cyclic load was calculated as $10 \%$ of ITS of each mixture. The resilient modulus was reported as the average of the first 5 consecutive cycles (having less than $1 \%$ change) after 100 cycles of preconditioning. These preconditioning cycles were applied first along the diametral axis followed by rotating the specimen $90^{\circ}$.

The total resilient modulus was calculated using the ASTM D 7369 equation stated below:

$$
\mathrm{MR}=\frac{P_{\text {cyclic }}}{\delta_{h} t}(I 1-I 2 \cdot \mu)
$$

$\mathrm{MR}=$ Total resilient modulus, $\mathrm{MPa}$

$t=$ Thickness of specimen, $\mathrm{mm}$

$\mu=$ Total Poisson's ratio

$$
\mu=0.15+\frac{0.35}{1+\exp (3.1849-0.04233 \times \text { Tem } p)}
$$

$P_{\text {cyclic }}=$ Peak cyclic load applied to the specimens, $\mathrm{N}$

$P_{\text {cyclic }}=\mathrm{P}_{\max }-\mathrm{P}_{\text {contact }}$

$\mathrm{P}_{\max }=$ Maximum applied load, $\mathrm{N}$

$\mathrm{P}_{\text {contact }}=$ Contact load, $\mathrm{N}$

$\delta h=$ Total recoverable horizontal deformation, $\mathrm{mm}$

$I 1, I 2=$ constants

\section{Results}

The results of characterizing tests on constituents of asphalt mixtures (with 40/50 grades and different aggregate gradations) are discussed first so that the effects of aggregate proportions of different gradations may be assessed on the resilient modulus linear and non-linear viscoelastic deformation. 


\subsection{Asphalt Binder Test Results}

The selected binder was analyzed by conventional tests such penetration, flash point, ductility, softening point and solubility. The results of conventional tests presented in Table 1a show that penetration 47 , flash point $335^{\circ} \mathrm{C}$, ductility $121 \mathrm{~cm}$, softening point $51.5^{\circ} \mathrm{C}$ and solubility $99.9 \%$ agree well with the ASTM D946 [49] and AASHTO M 20 [50] specifications for the penetration-graded asphalt binder. The results of performance-based asphalt binder properties are given in Table 1.

Asphalt binders were also characterized by performance tests at different conditions, i.e., rotational viscosity (original condition), dynamic shear rheometer (original, short-term aged and long-term aged) and bending beam rheometer (long-term aged). The rotational viscosities of the asphalt binder determined at seven temperatures (i.e., 125, 135, 145, $155,165,175$ and $185^{\circ} \mathrm{C}$ ) are given in Table $1 \mathrm{~b}$. The results revealed that the binder has a rotational viscosity lower than $3000 \mathrm{cp}$ at $135{ }^{\circ} \mathrm{C}$ and passed the criteria specified by AASHTO M 320.

The viscoelastic properties of the asphalt binder were determined using the DSR test, namely complex shear modulus $\left(G^{*}\right)$, phase angle $(\delta)$, rutting parameter $\left(G^{*} / \operatorname{Sin} \delta\right)$ and fatigue parameter $\left(\mathrm{G}^{*} \operatorname{Sin} \delta\right)$. The rutting parameter of the original and RFTO-aged as well as the fatigue parameter of the PAV-aged binder were used to specify the high-temperature performance grade as per AASHTO M 320 . The true grade temperature is $70.5^{\circ} \mathrm{C}$ in the original, $67.5^{\circ} \mathrm{C}$ in RTFO-aged and $23.5^{\circ} \mathrm{C}$ in PAV-aged condition. The BBR test at -6 to $-18{ }^{\circ} \mathrm{C}$ was performed after a long-term aging process. From the BBR test at three different temperatures, creep stiffness (S) and M-values were calculated. The $\mathrm{S}$ and M-values of binders were used to specify the low-temperature performance grade as per AASHTO $\mathrm{M}$ 320. The low temperature determined from the BBR test is $-10.1^{\circ} \mathrm{C}$. The binder was graded as PG 64-16.

\subsection{Aggregate Test Results}

Presented in Figure 3 are the gradation curves of WC and BC aggregates which fall in the aggregate size bands, i.e., D-4, D-5 based on ASTM D 3515, Superpave (SP-B) based on Superpave specifications, MS-2 based on Asphalt Institute Manual Series, DBM based on British standards and Superpave (SP-2) based on Superpave specifications. The gradation composition of WC and BC aggregates is presented in Table 2. The properties of aggregates are presented in Table 3.

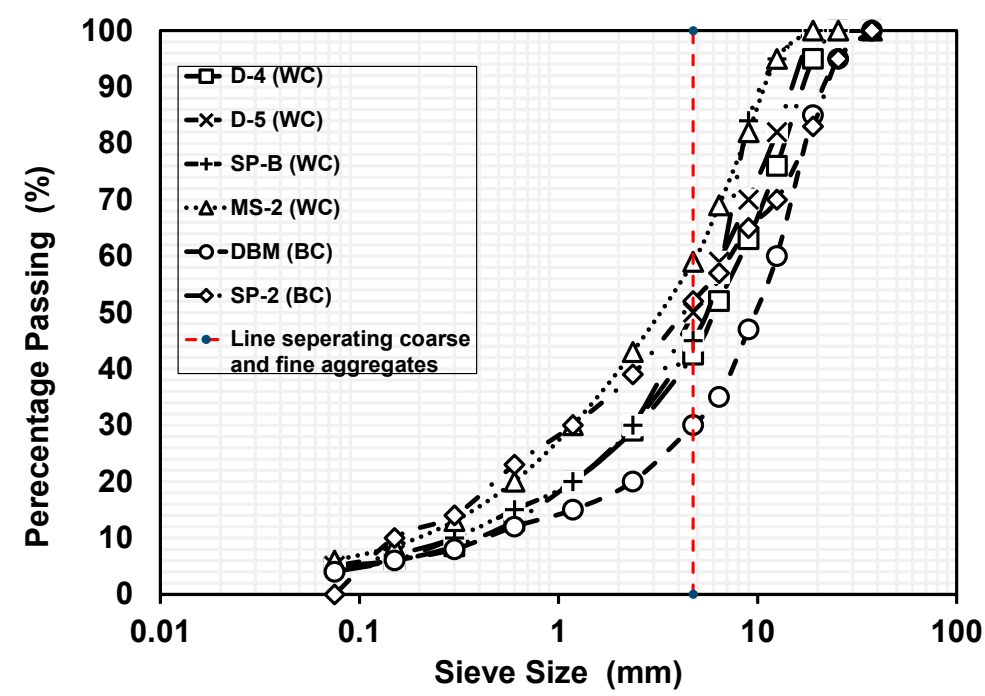

Figure 3. Gradation curves for wearing (WC) and base course (BC) mixtures. 
Table 2. Gradation composition of wearing and base course mixtures.

\begin{tabular}{ccccccc}
\hline & \multicolumn{7}{c}{ Gradation (\% Passing) } \\
\cline { 2 - 7 } Sieve Size $(\mathbf{m m})$ & \multicolumn{7}{c}{ Wearing Course (WC) } & \multicolumn{3}{c}{ Base Course (BC) } \\
& D-4 & D-5 & SP-B & MS-2 & DBM & SP-2 \\
\hline 37.5 & 100 & 100 & 100 & 100 & 100 & 100 \\
25.4 & 100 & 100 & 100 & 100 & 95 & 95 \\
19 & 95 & 100 & 100 & 100 & 85 & 83 \\
12.5 & 76 & 82 & 95 & 95 & 60 & 70 \\
9.0 & 63 & 70 & 84 & 82 & 47 & 65 \\
6.4 & 52 & 59 & 57 & 69 & 35 & 57 \\
4.75 & 42.5 & 50 & 45 & 59 & 30 & 52 \\
2.36 & 29 & 30 & 30 & 43 & 20 & 39 \\
1.18 & 20 & 20 & 20 & 30 & 15 & 30 \\
0.6 & 13 & 15 & 15 & 20 & 12 & 23 \\
0.3 & 8.5 & 10 & 10 & 13 & 8 & 14 \\
0.15 & 6 & 7 & 6 & 8.5 & 6 & 10 \\
0.075 & 5 & 5 & 4 & 6 & 4 & 5.5 \\
\hline
\end{tabular}

Table 3. Summary of aggregate physical properties.

\begin{tabular}{cccccccc}
\hline \multirow{2}{*}{ Test } & \multirow{2}{*}{ Standard } & D-4 & Wearing Course (WC) & \multicolumn{3}{c}{ Base Course (BC) } \\
& & SP-B & D-5 & MS-2 & DBM & SP-2 \\
\hline Fractured Faces (\%) & ASTM D 5821 [51] & 100 & 100 & 100 & 100 & 100 & 100 \\
Flakiness Index (\%) & ASTM D 4791 [52] & 5.42 & 6.21 & 6.87 & 7.32 & 5.78 & 7.48 \\
Elongation Index (\%) & ASTM D 4791 & 16.68 & 18.52 & 19.43 & 17.31 & 19.15 & 18.78 \\
Los Angeles Abrasion & ASTM C 131 [53] & 22.08 & 24.43 & 23.11 & 25.62 & 26.83 & 24.88 \\
Value (\%) & & 0.3 & 0.33 & 0.31 & 0.32 & 0.33 & 0.31 \\
Water Absorption (\%) & ASTM C 127 [54] & 0.87 & 0.59 & 0.61 & 0.43 & 0.93 & 0.82 \\
Soundness (\%) & ASTM C 88 [55] & 42 & 44 & 46 & 47 & 49 & 50 \\
Uncompacted Voids (\%) & ASTM C 1252 [56] & 80 & 79 & 79 & 78 & 77 & 78 \\
Sand Equivalent (\%) & ASTM D 2419 [57] & & & & & & \\
\hline
\end{tabular}

\subsection{Asphalt Mixture Test Results}

Properties investigated in this study were Marshall stability, flow, air voids (AV), voids in mineral aggregate (VMA), voids filled with asphalt (VFA), resilient modulus and indirect tensile strength as summarized in Table 4 . The results of volumetric properties and optimum asphalt content are presented in Table 5 . Stability ranging from 1170 to $3422 \mathrm{~kg}$, flow ranging from 11.2 to $13.8 \mathrm{~mm}$, VMA ranging from 12.19 to $12.75 \%$, VFA ranging from 60.16 to $66.75 \%$, $\mathrm{OBC}$ ranging from 3.87 to $4.65 \%$, unit weight ranging from 2360 to $2436 \mathrm{~kg} / \mathrm{m}^{3}$ and air voids at $4 \%$ were observed.

Table 4. Summary of test matrix of asphalt mixtures.

\begin{tabular}{ccccc}
\hline Gradations & MM & ITS $\left(25^{\circ} \mathbf{C}\right)$ & MR $\left(25^{\circ} \mathrm{C}\right)$ \\
\hline D-4 & & & $0.1 \mathrm{~s}$ & $0.3 \mathrm{~s}$ \\
SP-B & $\mathrm{x}$ & $\mathrm{x}$ & $\mathrm{x}$ & $\mathrm{x}$ \\
D-5 & $\mathrm{x}$ & $\mathrm{x}$ & $\mathrm{x}$ & $\mathrm{x}$ \\
MS-2 & $\mathrm{x}$ & $\mathrm{x}$ & $\mathrm{x}$ & $\mathrm{x}$ \\
DBM & $\mathrm{x}$ & $\mathrm{x}$ & $\mathrm{x}$ & $\mathrm{x}$ \\
SP-2 & $\mathrm{x}$ & $\mathrm{x}$ & $\mathrm{x}$ & $\mathrm{x}$ \\
\hline
\end{tabular}

${ }^{1}$ MM: Marshall mix, ITS: indirect tensile strength, MR: resilient modulus. 
Table 5. Volumetric properties of asphalt mixtures.

\begin{tabular}{|c|c|c|c|c|c|c|c|}
\hline Gradation & $\operatorname{VMA}^{1}(\%)$ & VFA (\%) & Stability (kg) & OBC (\%) & $\begin{array}{c}\text { Flow } \\
(0.25 \mathrm{~mm})\end{array}$ & $\begin{array}{l}\text { Unit Weight } \\
\qquad\left(\mathrm{kg} / \mathrm{m}^{3}\right)\end{array}$ & AV (\%) \\
\hline D-4 & 12.68 & 66.35 & 1305 & 3.99 & 12.2 & 2378 & 4 \\
\hline SP-B & 12.75 & 60.16 & 1250 & 3.87 & 13.4 & 2364 & 4 \\
\hline D-5 & 12.42 & 64.81 & 1215 & 4.11 & 13.8 & 2362 & 4 \\
\hline MS-2 & 13.72 & 66.75 & 1170 & 4.65 & 11.4 & 2360 & 4 \\
\hline DBM & 12.19 & 61.96 & 3422 & 3.88 & 12.6 & 2436 & 4 \\
\hline SP-2 & 12.42 & 61.38 & 2412 & 3.95 & 11.2 & 2401 & 4 \\
\hline
\end{tabular}

${ }^{1}$ VMA: Voids in mineral aggregates, VFA: voids filled with asphalt, OBC: optimum bitumen content, AV: air voids.

\subsection{Indirect Tensile Strength (ITS) Test Results}

In order to evaluate the strength of asphalt mixtures, the indirect tensile strength (ITS) test was performed at $25^{\circ} \mathrm{C}$. Presented in Figure 4 are the average indirect tensile strength values of three replicates of each mixture. The results represent the effect of aggregate gradation on the resistance of asphalt mixtures to tensile loads.

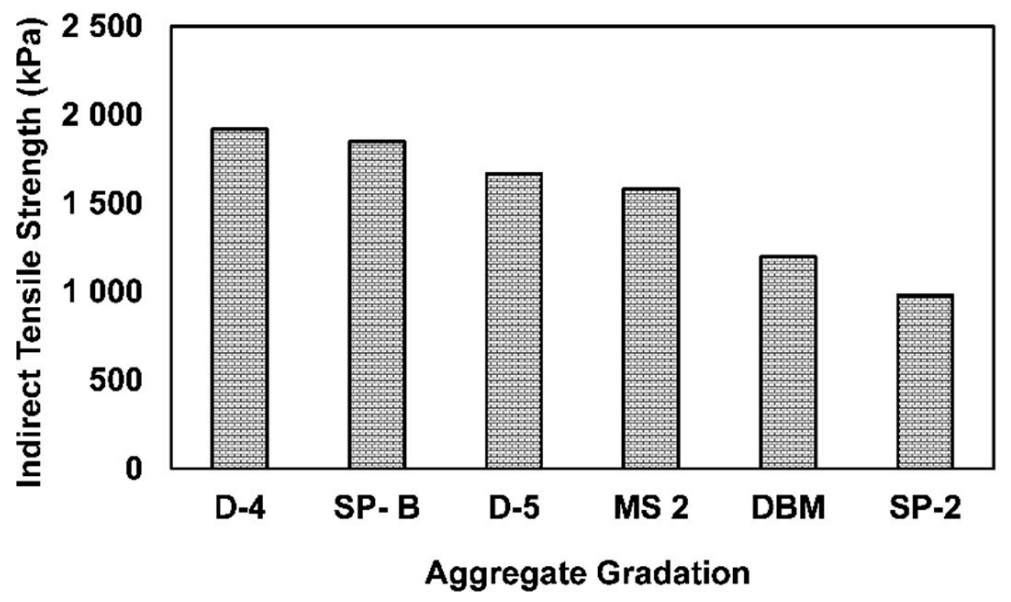

Figure 4. Indirect tensile strength of asphalt mixtures for different gradations at $25^{\circ} \mathrm{C}$.

\subsection{Resilient Modulus (MR) Test Results}

In order to evaluate the stiffness of asphalt mixtures, a resilient modulus (MR) test was performed at $25{ }^{\circ} \mathrm{C}$ for 0.1 and $0.3 \mathrm{~s}$ load durations. Haversine waveform was applied to simulate the dynamic movement of vehicles as per ASTM D 7369 for the evaluation of MRI and MRT. Two load durations, i.e., 0.1 and $0.3 \mathrm{~s}$, were used to study the effect of fast and slow loading rates respectively. The typical haversine deformation curves for asphalt mixtures for 0.1 and $0.3 \mathrm{~s}$ durations corresponding to six aggregate gradations are presented in Figures 5 and 6 . All data points are shown in Figures 5 and 6 for the complete picture of resulting behavior from dynamic loads. Data recording was performed as 500 data points per second for $0.1 \mathrm{~s}$ load duration by UTM software, as shown in Figure 7. The ASTM D 7369 method was used to analyze the haversine curves for the evaluation of instantaneous and total resilient moduli. Different loads were applied to specimens of asphalt mixtures formed from six aggregate gradations. 


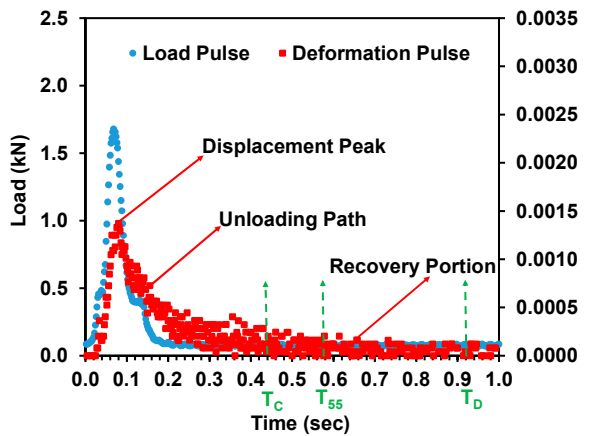

(a)

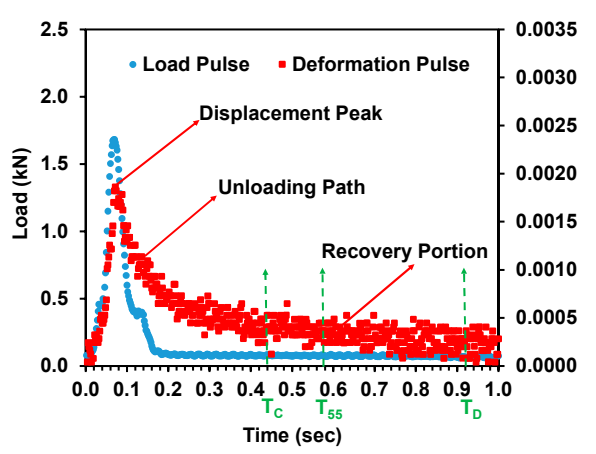

(c)

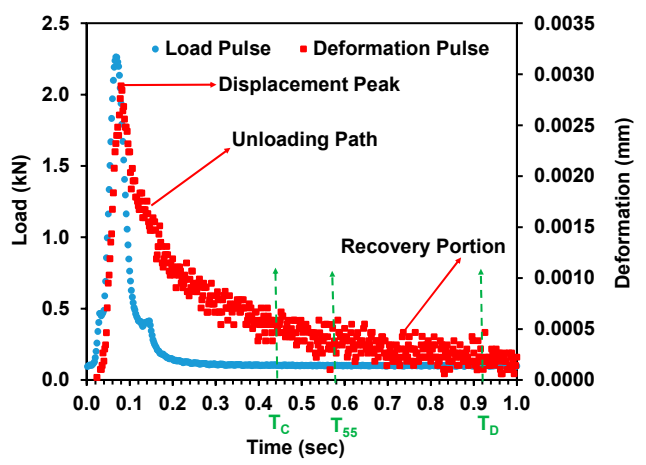

(e)

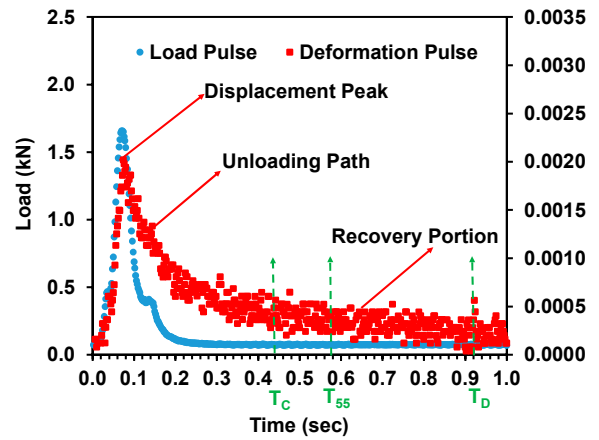

(b)

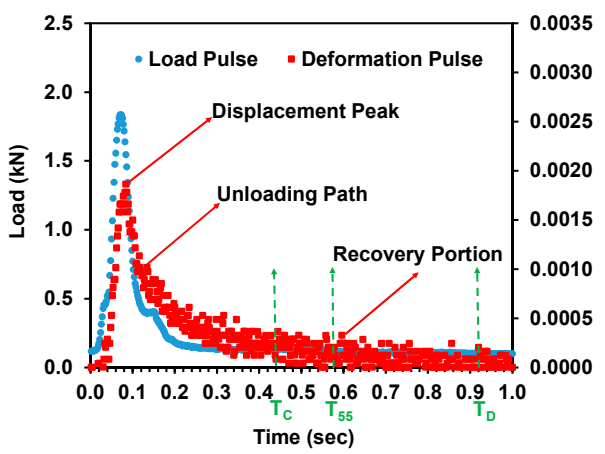

(d)

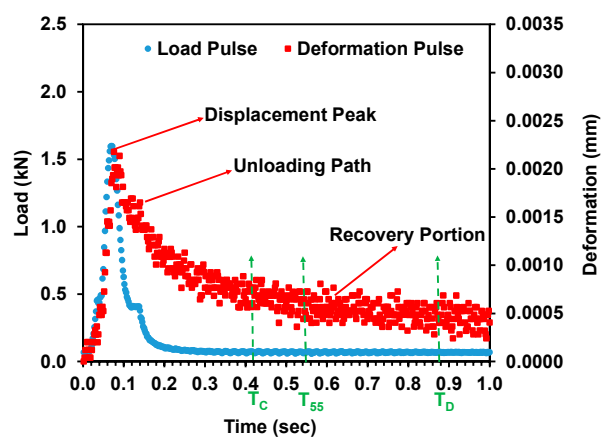

(f)

Figure 5. Typical haversine net deformation waveform at $25^{\circ} \mathrm{C}$ for $0.1 \mathrm{~s}$ load duration: (a) D-4 (WC), (b) SP-B (WC), (c) D-5 (WC), (d) MS-2 (WC), (e) DBM (BC) and (f) SP-2 (BC). 


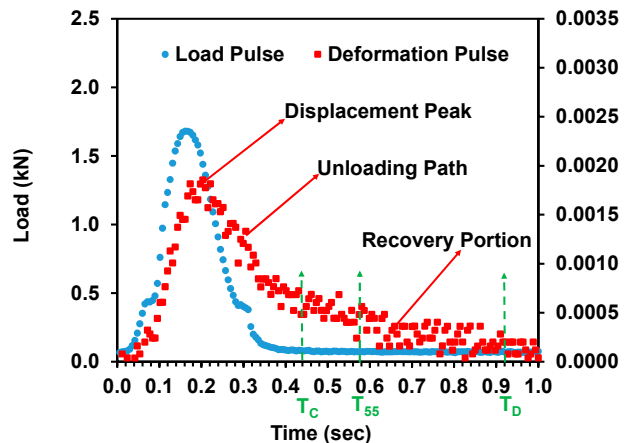

(a)

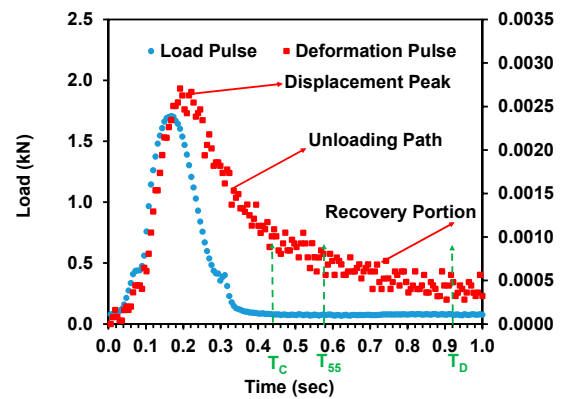

(c)

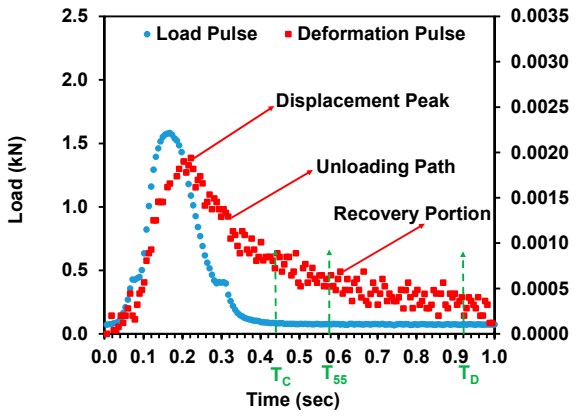

(e)

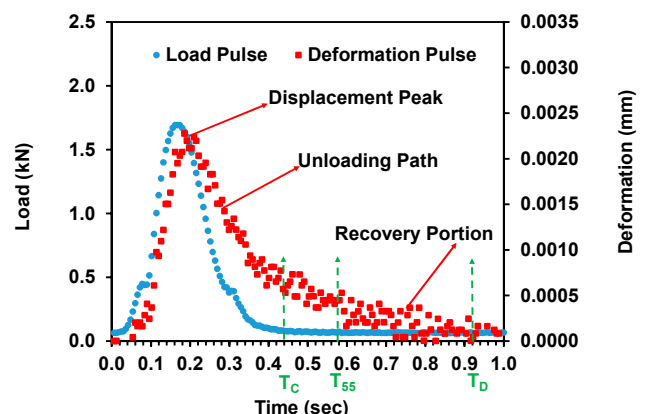

(b)

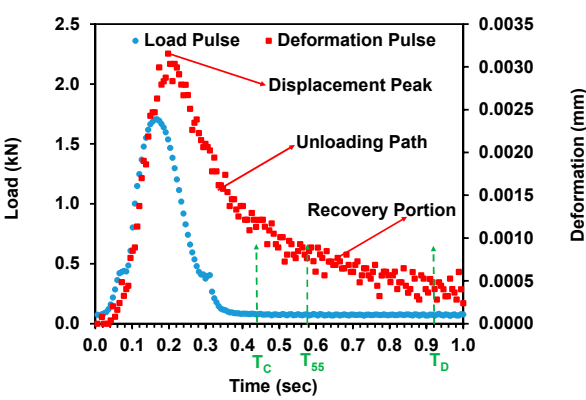

(d)

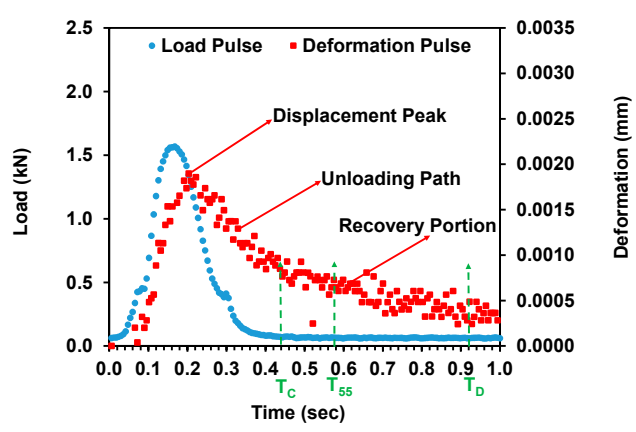

(f)

Figure 6. Typical haversine net deformation waveform at $25^{\circ} \mathrm{C}$ for $0.3 \mathrm{~s}$ load duration: (a) D-4 (WC), (b) SP-B (WC), (c) D-5 (WC), (d) MS-2 (WC), (e) DBM (BC) and (f) SP-2 (BC).

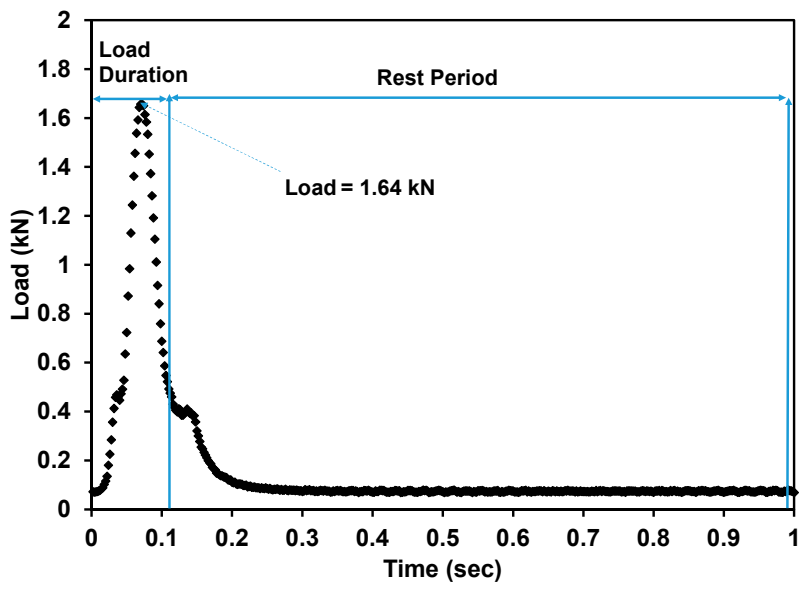

(a)

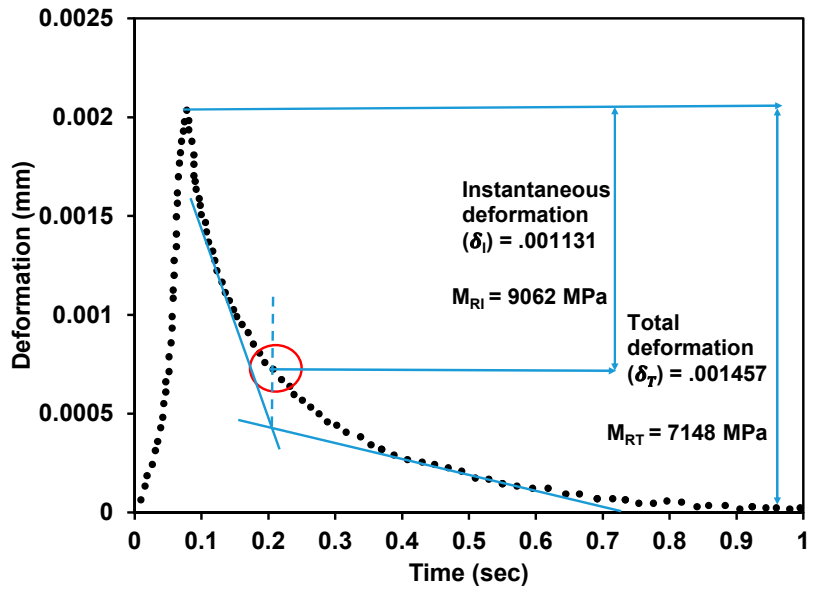

(b)

Figure 7. Cont. 


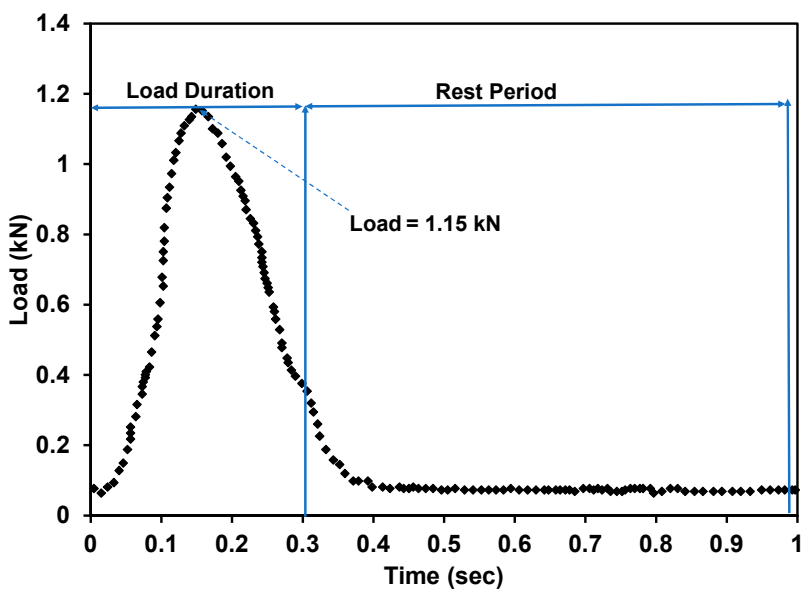

(c)

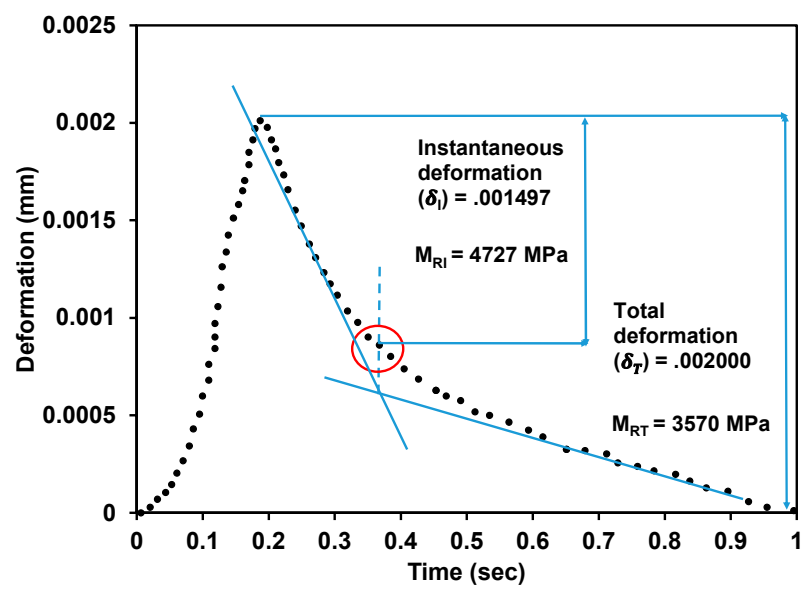

(d)

Figure 7. Typical haversine load and deformation waveforms at $25^{\circ} \mathrm{C}$ : (a) load SP-B (WC) at $0.1 \mathrm{~s}$, (b) deformation SP-B $(\mathrm{WC})$ at $0.1 \mathrm{~s},(\mathbf{c})$ load DBM (BC) at $0.3 \mathrm{~s}$ and $(\mathbf{d})$ deformation DBM (BC) at $0.3 \mathrm{~s}$.

\section{Discussion}

The gradations (Figure 3) are representative of typical construction extremes used in the pavement industry, so that the results of this research are utilized in the pavement construction industry in an optimal way. Different qualitative tests summarized in Table 3 show a summary of aggregate physical properties. Presented in Table 4 is the summary of test matrix of asphalt mixtures.

It can be observed from Table 5 that the stability value of D-4 is higher than that of other WC mixtures. The higher stability of D-4 may be credited to the coarser aggregate gradation of D-4. In BC mixtures, DBM showed higher stability as compared to SP-2. Based on the stability values, the strength of asphalt mixtures investigated in this study is in the order of DBM $>$ SP-2 for BC and D-4 > SP-B > D-5 > MS-2 for WC mixtures, as presented in Figure 8.

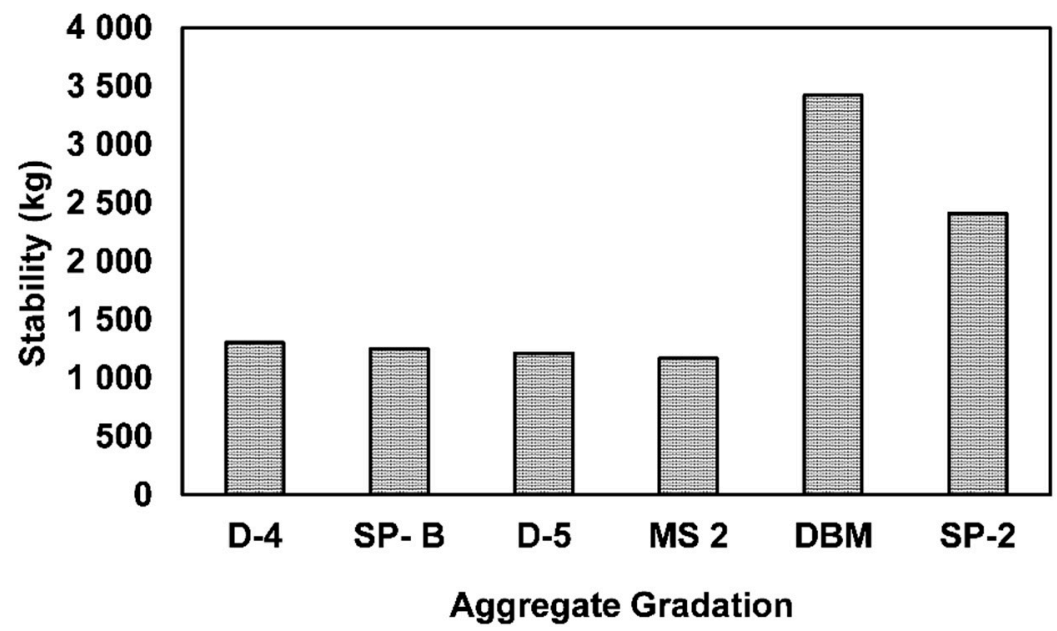

Figure 8. Stability of asphalt mixtures.

It can be seen from Figure 4 that the ITS value of the asphalt mixture with a D-4 aggregate proportion is more than that of other mixtures. The higher ITS of D-4 may be attributed to the coarser aggregate gradation as compared to other mixtures. Based on the ITS values, the strengths of asphalt mixtures evaluated in this study is in the order of D-4 > SP-B $>$ D-5 > MS $2>$ DBM $>$ SP-2. 
Presented in Figures 5 and 6 are the higher deformations that resulted from higher magnitude of loads. All asphalt mixtures show different patterns of deformation due to different aggregate proportions. These deformation curves are used for the evaluation of instantaneous and total resilient moduli from instantaneous and total deformations, respectively. The deformation curves of $0.1 \mathrm{~s}$ load duration shown in Figure 5 present lower deformation as compared with the curves of $0.3 \mathrm{~s}$ load duration shown in Figure 6, which infers that the moduli of $0.1 \mathrm{~s}$ load duration are comparatively higher than those of $0.3 \mathrm{~s}$ load duration.

The typical evaluation for instantaneous and total deformation along with corresponding instantaneous and total loads for $0.1 \mathrm{~s}$ load duration for asphalt mixture test specimens as per ASTM D 7369 are shown in Figure 7a,b. For simplicity and ease in calculations the mean value data points are shown with the loading and deformation curves for $0.1 \mathrm{~s}$ load duration. The analysis of deformation presents the complete calculation of the resilient moduli (instantaneous, MRI, and total, MRT). The higher values of MRI as $9062 \mathrm{MPa}$ is observed as compared with MRT as $7148 \mathrm{MPa}$ for $0.1 \mathrm{~s}$ load duration for a wearing course (WC) specimen. On the other hand, the curves presented in Figure 7c,d show the loading and deformation analysis of a base course (BC) specimen for $0.3 \mathrm{~s}$ load duration. The MRI and MRT are evaluated as $4727 \mathrm{MPa}$ and $3570 \mathrm{MPa}$, which are lower than the resilient moduli evaluated for $0.1 \mathrm{~s}$ load duration.

Figures 9a and 10a show an increase in instantaneous resilient modulus from $22.08 \%$ to $28.71 \%$ as compared with total resilient modulus. Presented in Figures $9 \mathrm{~b}$ and $10 \mathrm{~b}$, coarse aggregate proportions of $48 \%$ and $70 \%$ for base course (BC) and $41 \%, 50 \%, 55 \%$ and $57.5 \%$ for wearing course (WC) blended with a $40 / 50$ binder grade at $25^{\circ} \mathrm{C}$ at $0.1 \mathrm{~s}$ showed the total resilient modulus of 4107, 4590, 5586, 6074, 7148 and $7228 \mathrm{MPa}$ and instantaneous resilient modulus of 5795, 6388, 7448, 8682, 9062 and $9991 \mathrm{MPa}$, respectively. Presented in Figures $9 \mathrm{~b}$ and $10 \mathrm{~b}$, coarse aggregate proportions of $48 \%$ and $70 \%$ for base course and $41 \%$, $50 \%, 55 \%$ and $57.5 \%$ for wearing course blended with a $40 / 50$ binder grade at $25{ }^{\circ} \mathrm{C}$ at $0.3 \mathrm{~s}$ showed the total resilient modulus of $3130,3570,3848,4158,4625$ and $5234 \mathrm{MPa}$ and instantaneous resilient modulus of 4019, 4727, 5398, 5650, 6170 and $6718 \mathrm{MPa}$ respectively. The resilient modulus values are congruent with the resilient modulus of asphalt mixtures mentioned in past research [58] at 0.1 to $0.5 \mathrm{~Hz}$ from 15 to $20^{\circ} \mathrm{C}$. The results of this study also match other related previous studies $[59,60]$; however, there are some differences due to different asphalt mixtures, test conditions and material properties.

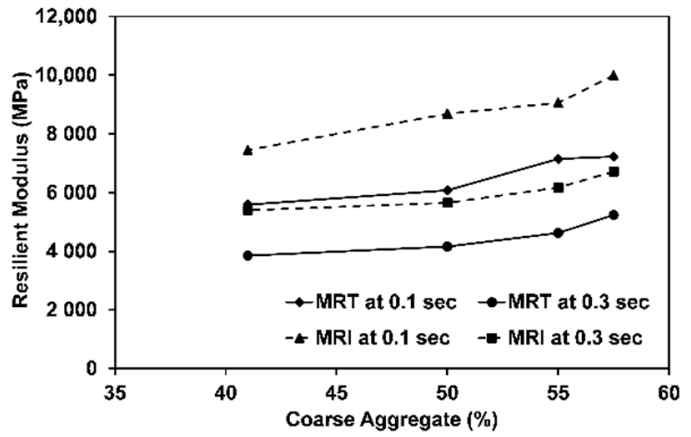

(a)

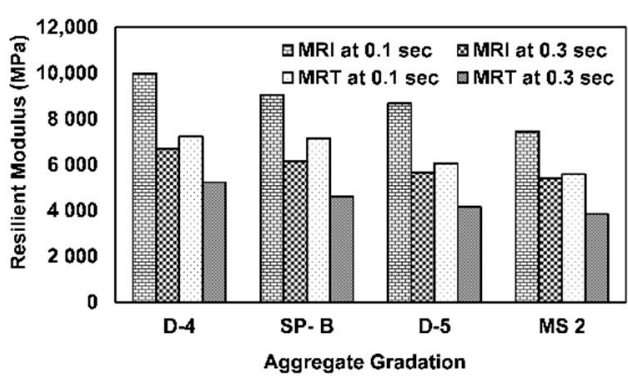

(b)

Figure 9. (a) Effect of coarse aggregate percentage on MRI and MRT of WC mixtures. (b) Effect of aggregate gradation on MRI and MRT of WC mixtures. 


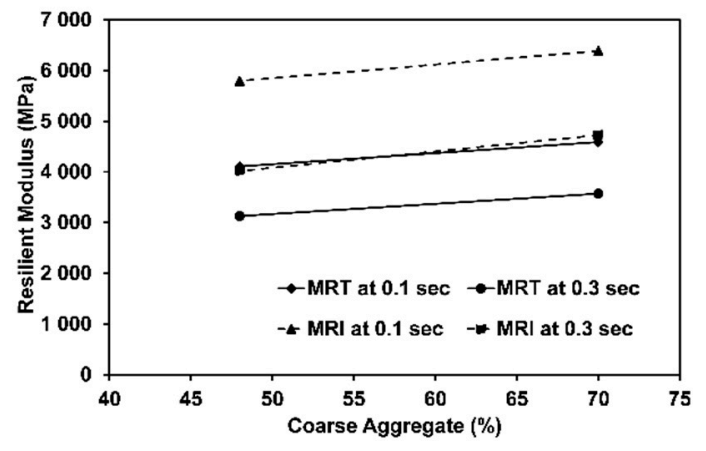

(a)

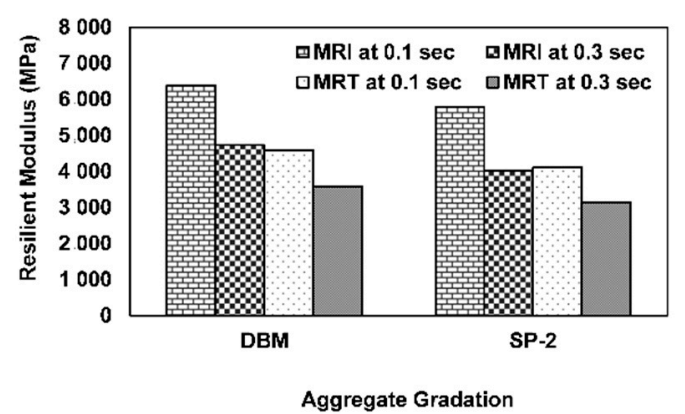

(b)

Figure 10. (a) Effect of coarse aggregate percentage on MRI and MRT of BC mixtures. (b) Effect of aggregate gradation on MRI and MRT of BC mixtures.

The indirect tensile strength (ITS) is correlated with MRI and MRT for 0.1 and $0.3 \mathrm{~s}$ load durations as presented in Figure 11. It is observed from Figure 11 that MRI and MRT increase with an increase in ITS for both WC and BC. It is observed that MRI showed higher values as compared with MRT due to the lesser extent of deformation used in MRI. It was observed that MRI increased by $25.5 \%$ for WC and $10.2 \%$ for BC for $0.1 \mathrm{~s}$ load duration, whereas MRT increased by $22.7 \%$ for $\mathrm{WC}$ and $11.8 \%$ for BC for $0.1 \mathrm{~s}$ load duration against ITS values ranging from $980 \mathrm{kPa}$ to $1920 \mathrm{kPa}$ at $25^{\circ} \mathrm{C}$ with a $40 / 50$ binder grade. It was also observed that MRI increased by $19.6 \%$ for WC and $17.6 \%$ for BC for $0.3 \mathrm{~s}$ load duration whereas MRT increased $26.5 \%$ for WC and $14 \%$ for BC for $0.3 \mathrm{~s}$ load duration against ITS values ranging from $980 \mathrm{kPa}$ to $1920 \mathrm{kPa}$ for $\mathrm{WC}$ and $\mathrm{BC}$ and $10.3 \%$ and $41.9 \%$ at $25^{\circ} \mathrm{C}$ with a $40 / 50$ binder grade.

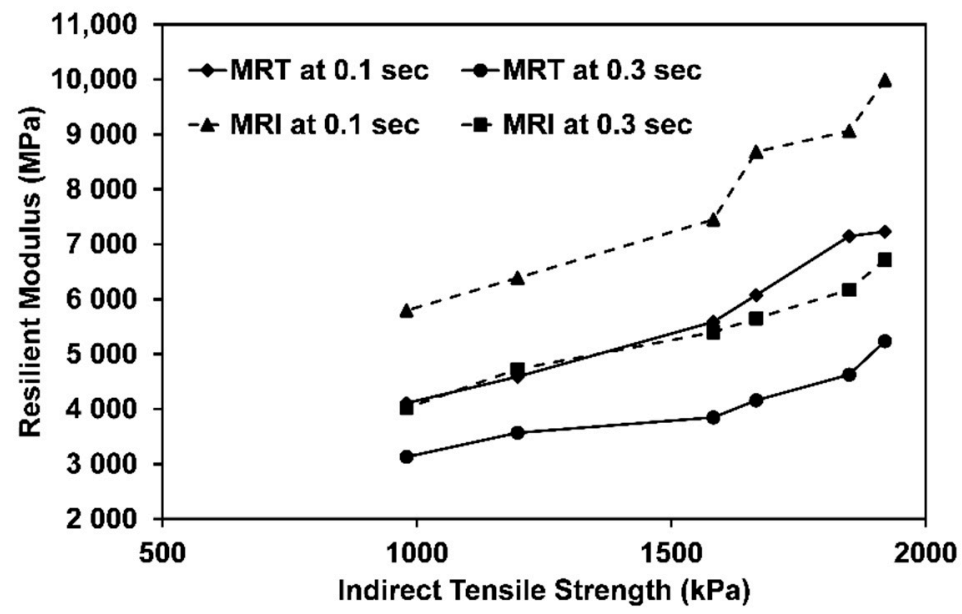

Figure 11. Effect of indirect tensile strength on MRI and MRT of asphalt mixture.

The relation presented in Figure 12 shows that MRI increased by $25.5 \%$ for WC and $10.2 \%$ for BC for $0.1 \mathrm{~s}$ load duration, whereas MRT increased by $22.7 \%$ for WC and $11.8 \%$ for BC for $0.1 \mathrm{~s}$ load duration against stability values of $1170 \mathrm{~kg}$ to $1305 \mathrm{~kg}$ for WC and $2412 \mathrm{~kg}$ to $3422 \mathrm{~kg}$ at $25^{\circ} \mathrm{C}$ with a $40 / 50$ binder grade. It was also observed from Figure 13 that MRI increased by $19.6 \%$ for WC and $17.6 \%$ for BC for $0.3 \mathrm{~s}$ load duration, whereas MRT increased by $26.5 \%$ for WC and $14 \%$ for BC for $0.3 \mathrm{~s}$ load duration against stability values of $1170 \mathrm{~kg}$ to $1305 \mathrm{~kg}$ for WC and $2412 \mathrm{~kg}$ to $3422 \mathrm{~kg}$ at $25^{\circ} \mathrm{C}$ with a $40 / 50$ binder grade. 


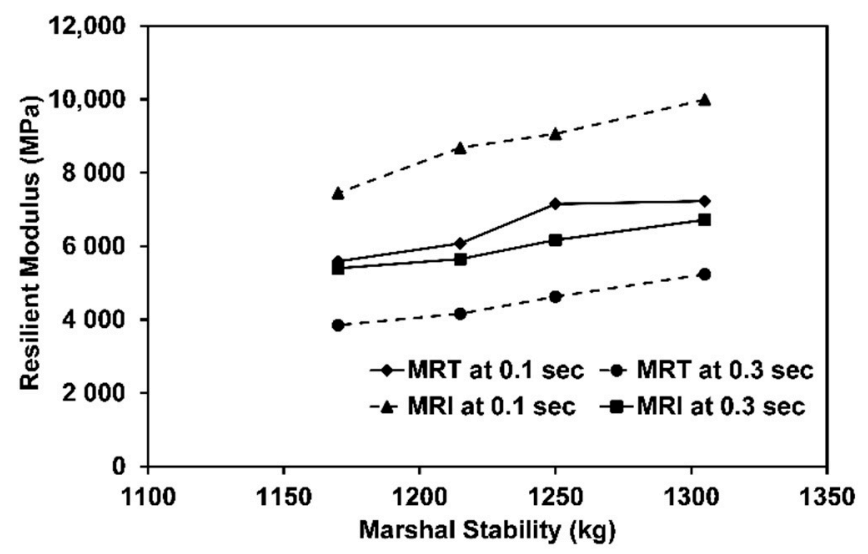

Figure 12. Effect of stability on MRI and MRT of WC mixtures.

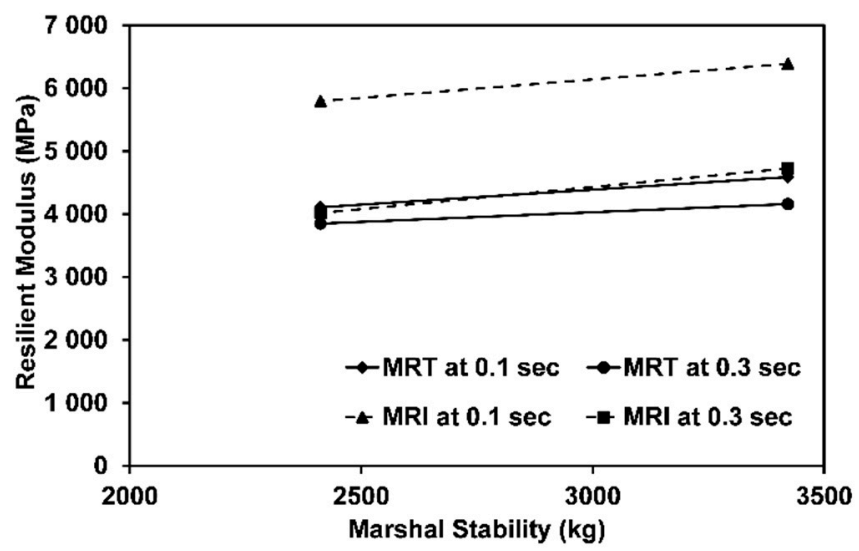

Figure 13. Effect of stability on MRI and MRT of BC mixtures.

It was observed from Figure 14 that MRI increased by $25.5 \%$ for WC and $10.2 \%$ for BC for $0.1 \mathrm{~s}$ load duration, whereas MRT increased by $22.7 \%$ for WC and $11.8 \%$ for BC for $0.1 \mathrm{~s}$ load duration against density (unit weight) values of $2360 \mathrm{~kg} / \mathrm{m}^{3}$ to $2378 \mathrm{~kg} / \mathrm{m}^{3}$ for WC and $2401 \mathrm{~kg} / \mathrm{m}^{3}$ to $2436 \mathrm{~kg} / \mathrm{m}^{3}$ at $25^{\circ} \mathrm{C}$ with a $40 / 50$ binder grade. It was also observed from Figure 15 that MRI increased by $19.6 \%$ for WC and $17.6 \%$ for BC for $0.3 \mathrm{~s}$ load duration whereas MRT increased by $26.5 \%$ for WC and $14 \%$ for BC for $0.3 \mathrm{~s}$ load duration against bulk density values of $2360 \mathrm{~kg} / \mathrm{m}^{3}$ to $2378 \mathrm{~kg} / \mathrm{m}^{3}$ for WC and $2401 \mathrm{~kg} / \mathrm{m}^{3}$ to $2436 \mathrm{~kg} / \mathrm{m}^{3}$ at $25{ }^{\circ} \mathrm{C}$ with a $40 / 50$ binder grade.

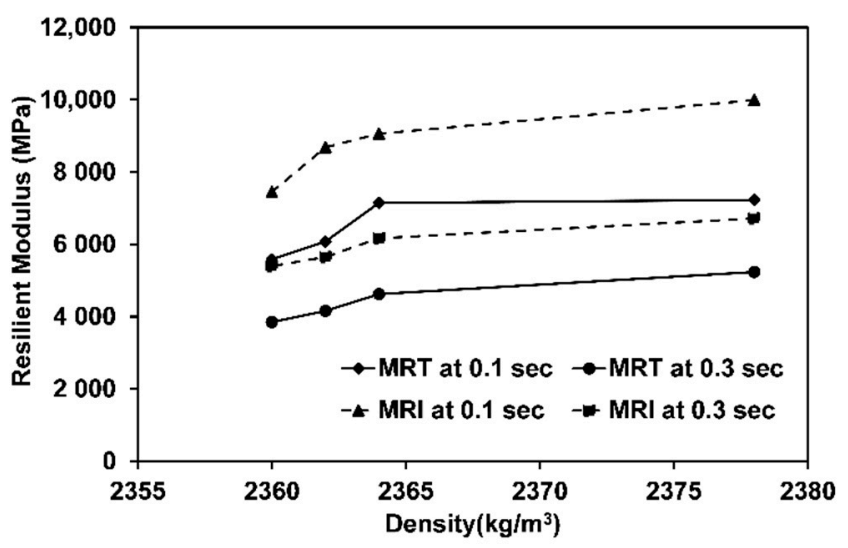

Figure 14. Effect of density on MRI and MRT of WC mixture. 


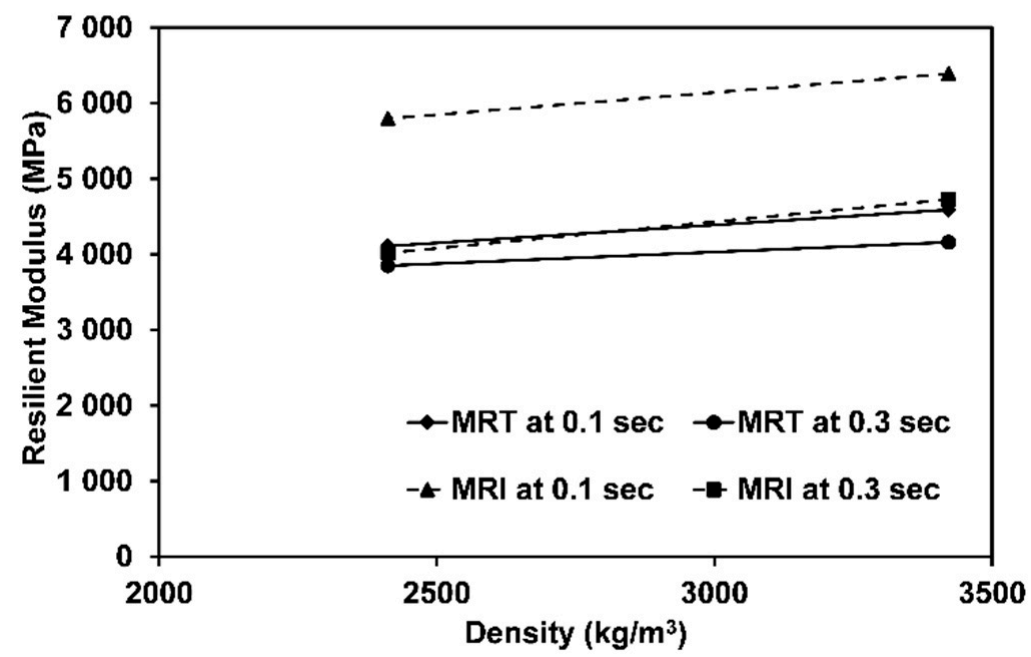

Figure 15. Effect of density on MRI and MRT of BC mixture.

Asphalt mixtures are basically viscoelastic in behavior [61]. Viscoelastic deformation in asphalt mixtures is observed to comprise of linear viscoelastic and non-linear viscoelastic portions. The non-linear viscoelastic deformation mainly falls after the removal of load and is the continuing recoverable portion of total deformation (ASTM D 7369). The linear portion is important in the sense that it is fully recovered and exhibits good quality of asphalt mixture. The reduced non-linear viscoelastic portion and enlarged linear viscoelastic region is seen in the case of improved asphalt mixtures, so that the maximum elastic property may be used against dynamic loading of vehicles on the flexible pavements. Figures 16 and 17 show the evaluation of linear and non-linear viscoelastic deformations resulting from dynamic loading applied in the haversine pattern for $0.1 \mathrm{~s}$ and $0.3 \mathrm{~s}$ load durations. It is also seen in Figures 16 and 17 that part of the non-linear viscoelastic deformation remains after the load removal, so this deformation may play a critical role in the initiation of deformation to be added to the non-recoverable part of the stress-deformation curve.

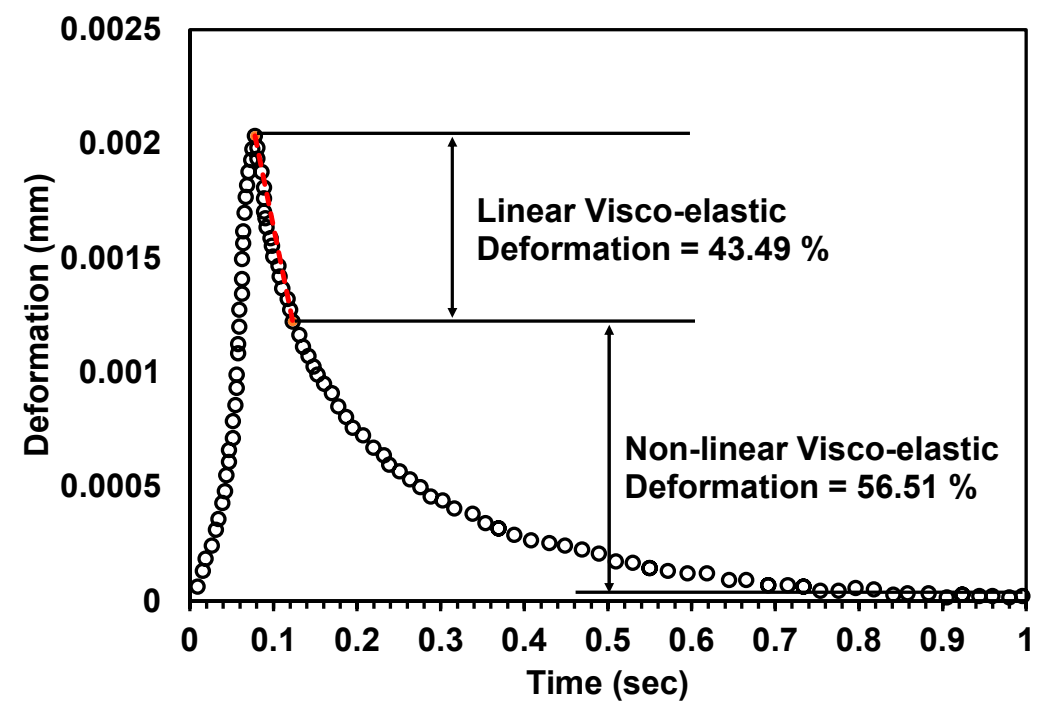

Figure 16. Linear viscoelastic deformation for WC at $0.1 \mathrm{~s}$ load duration. 


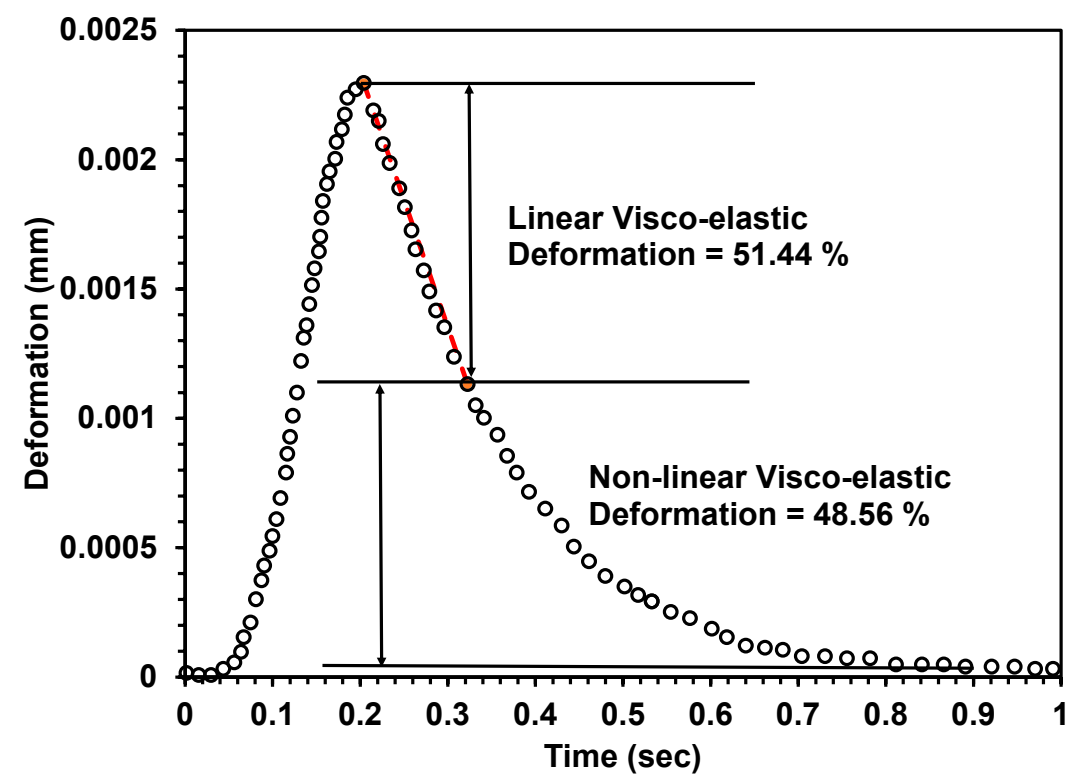

Figure 17. Linear viscoelastic deformation for BC at $0.3 \mathrm{~s}$ load duration.

In this research, the effect of an increase in coarse aggregate proportion for WC from $41 \%$ to $57.5 \%$ and for BC from $48 \%$ to $70 \%$ on linear and non-linear viscoelastic deformation is explored. An increase in linear viscoelastic deformation for $0.1 \mathrm{~s}$ duration is observed to be $54.6 \%$ to $68.2 \%$ for WC and $53.0 \%$ to $62.7 \%$ for BC, whereas non-linear viscoelastic deformation decreased from $45.4 \%$ to $31.8 \%$ for WC and from $47.0 \%$ to $37.3 \%$ for BC. Likewise, $0.3 \mathrm{~s}$ load duration was also analyzed for the same aggregate proportions. It was observed that linear viscoelastic deformation increased from 58.1\% to $69.1 \%$ for WC and $64.3 \%$ to $69.2 \%$ for BC, whereas non-linear viscoelastic deformation decreased from $41.9 \%$ to $30.9 \%$ for WC and $35.7 \%$ to $30.8 \%$ for BC.

In brief, the effect of an increase in percent coarse aggregate (PCA) from $48 \%$ to $70 \%$ for base course and $41 \%$ to $57.5 \%$ for wearing course was observed for MRI, MRT, linear viscoelastic deformation and non-linear viscoelastic deformation of asphalt mixtures with a $40 / 50$ binder grade at $25^{\circ} \mathrm{C}$ for 0.1 and $0.3 \mathrm{~s}$ load durations. The results show that MRI increased from $10.2 \%$ to $25.5 \%$ and MRT increased from $11.8 \%$ to $26.5 \%$, depicting that resilience of asphalt mixtures increases with an increase in PCA. This finding is significant in the sense that equivalent effects of an increase in PCA are observed for instantaneous and total duration of load application. Furthermore, it was observed that an increase in PCA increased linear viscoelastic deformation from $53 \%$ to $69.2 \%$ and decreased the non-linear viscoelastic deformation from $47.0 \%$ to $30.8 \%$ for asphalt mixtures, which is a novel finding in the area of flexible pavement construction. It is an interesting finding in the sense that an increase in PCA decreases the non-linearity in stress-strain behavior of asphalt mixtures. The decrease in non-linearity further enhances the resistance to permanent deformation of flexible pavements. The results also show that an increase in PCA causes an increase in ITS of $18.2 \%$ for BC and $17.6 \%$ for WC, from which it is inferred that an increase in PCA shows almost equivalent effects in $\mathrm{BC}$ and $\mathrm{WC}$.

It is worth mentioning that the present study includes tests for the analysis and determination of aggregate and resilient properties of asphalt mixtures, which is defined collectively as multiscale evaluation. Regarding multiscale evaluation, it can be observed that detailed analysis of aggregate characteristics was conducted before resilient modulus, ITS and stability tests on asphalt mixtures. The aggregate was analyzed for different tests as described in Table 3 which shows that soundness values range from 0.43 to 0.93 and uncompacted voids range from 42 to 50 . The resilient modulus test was carried out on asphalt mixtures for the determination of linear viscoelastic and non-linear viscoelastic properties. 
In order to investigate the relationship between indirect tensile strength (ITS), stability, percent coarse aggregate (PCA), MRI and MRT, test results were analyzed using MINITAB19 statistical software. On the basis of this analysis, the relationships found between these parameters are summarized in Table 6 . These equations can be used to estimate the MRI and MRT values of WC and BC asphalt mixtures at 0.1 and $0.3 \mathrm{~s}$ load durations.

Table 6. Regression models for estimation of MRI and MRT for BC and WC asphalt mixtures.

\begin{tabular}{|c|c|c|c|}
\hline Mix Type & Load Duration & Regression Model & $\mathbf{R}^{2}$ \\
\hline \multirow{4}{*}{ WC } & \multirow{2}{*}{$0.1 \mathrm{~s}$} & MRI $=-10983-3.537$ ITS + 81.80 PCA + 17.67 Stability & 0.91 \\
\hline & & $\mathrm{MRT}=3704+6.504$ ITS +35.79 PCA -8.446 Stability & 0.88 \\
\hline & \multirow{2}{*}{$0.3 \mathrm{~s}$} & MRI $=-6913+2.133$ ITS -36.52 PCA + 8.916 Stability & 0.86 \\
\hline & & $\mathrm{MRT}=-9630+1.370$ ITS -32.30 PCA +10.80 Stability & 0.89 \\
\hline \multirow{4}{*}{$\mathrm{BC}$} & \multirow[b]{2}{*}{$0.1 \mathrm{~s}$} & $\mathrm{MRI}=2173+4.614 \mathrm{ITS}-18.75 \mathrm{PCA}$ & 0.87 \\
\hline & & $\mathrm{MRT}=1058+3.957 \mathrm{ITS}-17.27 \mathrm{PCA}$ & 0.81 \\
\hline & \multirow{2}{*}{$0.3 \mathrm{~s}$} & $\mathrm{MRI}=-908.3+6.709 \mathrm{ITS}-34.32 \mathrm{PCA}$ & 0.84 \\
\hline & & $\mathrm{MRT}=1573$ + $1.185 \mathrm{ITS}+8.245$ PCA & 0.83 \\
\hline
\end{tabular}

MRI = Instantaneous resilient modulus, MPa; MRT = total resilient modulus, $\mathrm{MPa}$; ITS = indirect tensile strength, $\mathrm{kPa}$; PCA = percent coarse aggregate, $\%$; Stability $=$ Marshall stability, kg.

The regression models presented in Table 6 were developed for mixtures incorporating a $40 / 50$ grade binder tested at $25^{\circ} \mathrm{C}$; therefore, their applicability is only limited to matching materials and testing conditions.

\section{Conclusions}

The effect of an increase in percent coarse aggregate (PCA) from $48 \%$ to $70 \%$ for base course and $41 \%$ to $57.5 \%$ for wearing course was studied for instantaneous resilient modulus (MRI), total resilient modulus (MRT), linear viscoelastic deformation and nonlinear viscoelastic deformation of asphalt mixtures with a $40 / 50$ binder grade at $25^{\circ} \mathrm{C}$ for 0.1 and $0.3 \mathrm{~s}$ load durations. The following was observed:

- MRI increased from $10.2 \%$ to $25.5 \%$ and MRT increased from $11.8 \%$ to $26.5 \%$, depicting that the resilience of asphalt mixtures increases with an increase in PCA.

- An increase in PCA increased linear viscoelastic deformation from $53 \%$ to $69.2 \%$ and decreased the non-linear viscoelastic deformation from $47.0 \%$ to $30.8 \%$ for asphalt mixtures, which is a novel finding in the area of flexible pavement construction.

- An increase in PCA results in an increase of ITS of $18.2 \%$ for BC and $17.6 \%$ for WC, from which it is inferred that an increase in PCA shows an almost equivalent effect in $\mathrm{BC}$ and WC.

- The relations of PCA, ITS and stability versus MRI and MRT are presented using MINITAB-19 statistical software, for rapid and cost-effective assessment of response of flexible pavements using simple laboratory tests.

Author Contributions: Conceptualization, M.A.R. and A.H.K.; methodology, M.A.R.; validation, M.A.R., A.H.K. and Z.u.R.; formal analysis, M.A.R.; investigation, M.A.R.; resources, A.I.; writingoriginal draft preparation, M.A.R.; writing—review and editing, M.A.R., A.H.K., Z.u.R., Z.M. and A.I.; supervision, A.H.K. All authors have read and agreed to the published version of the manuscript.

Funding: The authors are grateful to Highway Research and Training Center (HRTC), National Highway Authority (NHA), Pakistan, for necessary funding.

Institutional Review Board Statement: Not applicable.

Informed Consent Statement: Not applicable.

Data Availability Statement: The data presented in this study are available on request from the corresponding author.

Acknowledgments: The authors would like to thank HRTC NHA and the department of transportation engineering and management for their support. 
Conflicts of Interest: The authors declare no conflict of interest.

\section{References}

1. ASTM D7369. Standard Test Method for Determining the Resilient Modulus of Bituminous Mixtures by Indirect Tension Test; ASTM International: West Conshohocken, PA, USA, 2020.

2. Shalaby, A.; Liske, T.; Kavussi, A. Comparing back-calculated and laboratory resilient moduli of bituminous paving mixtures. Can. J. Civ. Eng. 2004, 31, 988-996. [CrossRef]

3. Loulizi, A.; Flintsch, G.W.; Al-Qadi, I.L.; Mokarem, D.W. Comparing Resilient Modulus and Dynamic Modulus of Hot-Mix Asphalt as Material Properties for Flexible Pavement Design. Trans. Res. Rec. 2006, 23, 161-170. [CrossRef]

4. $\quad$ AASHTO. Guide for Design of Pavement Structures, 157; AASHTO: Washington, DC, USA, 1993.

5. Tahmoorian, F.; Yeaman, J.; Mirzababaei, M. Comparisons of the Resilient Moduli of Asphalt Mixes Containing Recycled Materials through Empirical and Experimental Methods. J. Mat. Civ. Eng. 2020, 32, 04020255. [CrossRef]

6. Timm, D.H.; Peters-Davis, K. Recalibration of the Asphalt Layer Coefficient; NCAT Rep. No. 09-03; National Center for Asphalt Technology: Auburn, AL, USA, 2009.

7. Clyne, T.R.; Li, X.; Marasteanu, M.O.; Skok, E.L. Dynamic and Resilient Modulus of Mn/DOT Asphalt Mixtures; No. MN/RC-2003-09; University of Minnesota: Twin Cities, MN, USA, 2003.

8. Kaseer, F.; Yin, F.; Arámbula-Mercado, E.; Martin, A.E. Stiffness characterization of asphalt mixtures with high recycled material content and recycling agents. Transp. Res. Rec. 2017, 2633, 58-68. [CrossRef]

9. Mamlouk, M.; Sarofim, R.T. Modulus of asphalt mixtures-an unresolved dilemma. Transp. Res. Rec. 1988, 1711, $193-198$.

10. Czech, K.; Gardziejczyk, W. Dynamic Stiffness of Bituminous Mixtures for the Wearing Course of the Road Pavement-A Proposed Method of Measurement. Materials 2020, 13, 1973. [CrossRef]

11. Iwański, M. Effect of Hydrated Lime on Indirect Tensile Stiffness Modulus of Asphalt Concrete Produced in Half-Warm Mix Technology. Materials 2020, 13, 4731. [CrossRef]

12. Mackiewicz, P.; Maczka, E. The Impact of Water and Road Salt with Anti-Caking Agent on the Stiffness of Select Mixes Used for the Road Surface. Materials 2021, 14, 1345. [CrossRef]

13. Wu, Z.; Zhang, C.; Xiao, P.; Li, B.; Kang, A. Performance Characterization of Hot Mix Asphalt with High RAP Content and Basalt Fiber. Materials 2020, 13, 3145. [CrossRef]

14. Li, L.; Jiang, X.; Lin, Y.; Yan, H. A Prediction Model on Viscoelastic Fatigue Damage of Asphalt Mixture. Materials 2020, 13, 3782. [CrossRef]

15. Złotowska, M.; Nagórski, R.; Błażejowski, K. Concept of Similarity Method for Prediction of Fatigue Life of Pavement Structures with HiMA Binder in Asphalt Layers. Materials 2021, 14, 480. [CrossRef] [PubMed]

16. Crisman, B.; Ossich, G.; Lorenzi, L.D.; Bevilacqua, P.; Roberti, R. A Laboratory Assessment of the Influence of Crumb Rubber in Hot Mix Asphalt with Recycled Steel Slag. Sustainability 2020, 12, 8045. [CrossRef]

17. Woszuk, A.; Wróbel, M.; Bandura, L.; Franus, W. Brick Debris Dust as an Ecological Filler and Its Effect on the Durability of Asphalt Mix. Materials 2020, 13, 5023. [CrossRef] [PubMed]

18. Skotnicki, L.; Kuźniewski, J.; Szydlo, A. Stiffness Identification of Foamed Asphalt Mixtures with Cement, Evaluated in Laboratory and In Situ in Road Pavements. Materials 2020, 13, 1128. [CrossRef]

19. Chomicz-Kowalska, A.; Maciejewski, K.; Iwański, M.M. Study of the Simultaneous Utilization of Mechanical Water Foaming and Zeolites and Their Effects on the Properties of Warm Mix Asphalt Concrete. Materials 2020, 13, 357. [CrossRef] [PubMed]

20. Skaf, M.; Pasquini, E.; Revilla-Cuesta, V.; Ortega-López, V. Performance and Durability of Porous Asphalt Mixtures Manufactured Exclusively with Electric Steel Slags. Materials 2019, 12, 3306. [CrossRef]

21. White, G. A Synthesis on the Effects of Two Commercial Recycled Plastics on the Properties of Bitumen and Asphalt. Sustainability 2020, 12, 8594. [CrossRef]

22. Omranian, S.R.; Hamzah, M.O.; Pipintakos, G.; Van den bergh, W.; Vuye, C.; Hasan, M.R.M. Effects of Short-Term Aging on the Compactibility and Volumetric Properties of Asphalt Mixtures Using the Response Surface Method. Sustainability 2020, $12,6181$. [CrossRef]

23. Elliot, R.P.; Ford, M.C.; Ghanim, M.; Tu, Y.F. Effect of Aggregate Gradation Variation on Asphalt Concrete Mix Properties. Trans. Res. Rec. 1991, 1317, 52-60.

24. Lim, C.T.; Tan, S.A. Specimen size effects on the diametrical mechanical testing of cylindrical asphalt mixes. J. Test. Eval. 1995, $23,436-441$.

25. Tongyan, P.; Tutumluer, E.; Carpenter, S. Effect of coarse aggregate morphology on the resilient modulus of hot-mix asphalt, Trans. Res. Rec. 2005, 1929, 1-9.

26. Brown, E.R.; Bassett, C.E. Effects of maximum aggregate size on rutting potential and other properties of asphalt-aggregate mixtures. Trans. Res. Rec. 1990, 1259, 107-119.

27. Bagampadde, U.; Isacsson, U.; Kiggundu, B.M. Impact of bitumen and aggregate composition on stripping in bituminous mixtures. Mater. Struct. 2006, 39, 303-315. [CrossRef]

28. Luo, R.; Liu, H.; Zhang, Y. Characterization of linear viscoelastic, nonlinear viscoelastic and damage stages of asphalt mixtures. Constr. Build. Mater. 2016, 125, 72-80. [CrossRef] 
29. Ban, H.; Im, S.; Kim, Y.R. Non-linear viscoelastic approach to model damage-associated performance behaviour of asphaltic mixture and pavement structure. Can. J. Civ. Eng. 2013, 40, 313-323. [CrossRef]

30. Luo, X. Characterization of Fatigue Cracking and Healing of Asphalt Mixtures. Ph. D. Thesis, Texas A \& M University, College Station, TX, USA, 2012.

31. ASTM D5. Standard Test Method for Penetration of Bituminous Materials; ASTM International: West Conshohocken, PA, USA, 2020.

32. ASTM D36. Standard Test Method for Softening Point of Bitumen (Ring-and-Ball Apparatus); ASTM International: West Conshohocken, PA, USA, 2014.

33. ASTM D113. Standard Test Method for Ductility of Asphalt Materials; ASTM International: West Conshohocken, PA, USA, 2017.

34. ASTM D92. Standard Test Method for Flash and Fire Points by Cleveland Open Cup Tester; ASTM International: West Conshohocken, PA, USA, 2018.

35. AASHTO-M 320. Standard Specification for Performance-Graded Asphalt Binder; American Association of State Highway and Transportation Officials: Washington, DC, USA, 2017.

36. AASHTO-T 316. Standard Method of Test for Viscosity Determination of Asphalt Binder Using Rotational Viscometer; American Association of State Highway and Transportation Officials: Washington, DC, USA, 2019.

37. AASHTO-T 315. Standard Method of Test for Determining the Rheological Properties of Asphalt Binder Using a Dynamic Shear Rheometer; American Association of State Highway and Transportation Officials: Washington, DC, USA, 2010.

38. AASHTO-T 240. Standard Method of Test for Effect of Heat and Air on a Moving Film of Asphalt Binder (Rolling Thin-Film Oven Test); American Association of State Highway and Transportation Officials: Washington, DC, USA, 2013.

39. AASHTO-R 28. Standard Practice for Accelerated Aging of Asphalt Binder Using a Pressurized Aging Vessel (PAV); American Association of State Highway and Transportation Officials: Washington, DC, USA, 2012.

40. AASHTO-T 313. Standard Method of Test for Determining the Flexural Creep Stiffness of Asphalt Binder Using the Bending Beam Rheometer (BBR); American Association of State Highway and Transportation Officials: Washington, DC, USA, 2011.

41. Abbas, S.; Munir, M.J.; Kazmi, S.M.S.; Khitab, A.; Ashiq, S.Z.; Arshad, M.T. Engineering characteristics of widely used coarse aggregates in Pakistan: A comparative study. Pak. J. Eng. Appl. Sci. 2017, 20, 85-93.

42. ASTM D3515. Standard Specification for Hot-Mixed, Hot-Laid Bituminous Paving Mixtures; ASTM International: West Conshohocken, PA, USA, 2009.

43. Halladay, M. The Strategic Highway Research Program: An Investment that Has Paid Off; Public Roads: Washington, DC, USA, 1998; Volume 61.

44. Asphalt Institute, Mix Design Methods for Asphalt Concrete and Other Hot-Mix Types; Asphalt Institute: Lexington, KY, USA, 1997.

45. BS EN 13108-1 2016: Part 1. Bituminous Mixtures Materials Specification-Asphalt Concrete; European Committee for Standardization, British Standards Institution: London, UK, 2016.

46. ASTM D6926. Standard Practice for Preparation of Asphalt Mixture Specimens Using Marshall Apparatus; ASTM International: West Conshohocken, PA, USA, 2010.

47. AASHTO-T 312. Standard Method of Test for Preparing and Determining the Density of Asphalt Mixture Specimens by Means of the Superpave Gyratory Compactor; American Association of State and Washington Highway Transportation Officials: Washington, DC, USA, 2019.

48. ASTM D6931. Standard Test Method for Indirect Tensile (IDT) Strength of Asphalt Mixtures; ASTM International: West Conshohocken, PA, USA, 2007.

49. ASTM D 946/D946 M-20. Standard Specification for Penetration-Graded Asphalt Binder for USE in Pavement Construction; ASTM International: West Conshohocken, PA, USA, 2020.

50. AASHTO-M 20. Standard Specification for Penetration-Graded Asphalt Cement; American Association of State Highway and Transportation Officials: Washington, DC, USA, 1970.

51. ASTM D5821-13 2017. Standard Test Method for Determining the Percentage of Fractured Particles in Coarse Aggregate; ASTM International: West Conshohocken, PA, USA, 2017.

52. ASTM D4791-19. Standard Test Method for Flat Particles, Elongated Particles, or Flat and Elongated Particles in Coarse Aggregate; ASTM International: West Conshohocken, PA, USA, 2019.

53. ASTM C131/C131M-20. Standard Test Method for Resistance to Degradation of Small-Size Coarse Aggregate by Abrasion and Impact in the Los Angeles Machine; ASTM International: West Conshohocken, PA, USA, 2020.

54. ASTM C127-15. Standard Test Method for Relative Density (Specific Gravity) and Absorption of Coarse Aggregate; ASTM International: West Conshohocken, PA, USA, 2015.

55. ASTM C88/C88M-18. Standard Test Method for Soundness of Aggregates by Use of Sodium Sulphate or Magnesium Sulphate; ASTM International: West Conshohocken, PA, USA, 2018.

56. ASTM C 1252-17. Standard Test Methods for Uncompacted Void Content of Fine Aggregate (as Influenced by Particle Shape, Surface Texture, and Grading); ASTM International: West Conshohocken, PA, USA, 2017.

57. ASTM D 2419-14. Standard Test Method for Sand Equivalent Value of Soils and Fine Aggregate; ASTM International: West Conshohocken, PA, USA, 2017.

58. Li, P.; Zheng, M.; Wang, F.; Che, F.; Li, H.; Ma, Q.; Wang, Y. Laboratory performance evaluation of high modulus asphalt concrete modified with different additives. Adv. Mater. Sci. Eng. 2017, 217, 7236153. [CrossRef] 
59. Lytton, R.L.; Gu, F.; Zhang, Y.; Luo, X. Characteristics of undamaged asphalt mixtures in tension and compression. Int. J. Pav. Eng. 2018, 19, 192-204. [CrossRef]

60. Sun, Y.; Gu, B.; Gao, L.; Li, L.; Guo, R.; Yue, Q.; Wang, J. Viscoelastic mechanical responses of HMAP under moving load. Materials 2018, 11, 2490. [CrossRef] [PubMed]

61. Mackiewics, P.; Szydlo, A. Viscoelastic parameters of asphalt mixtures identified in static and dynamic tests. Materials 2019, 12, 2084. [CrossRef] 